\title{
miR-154-5p Affects the TGF $\beta 1 /$ Smad3 Pathway on the Fibrosis of Diabetic Kidney Disease via Binding E3 Ubiquitin Ligase Smurf1
}

\author{
Che Bian $\mathbb{D}^{1},{ }^{1}$ Zhilin Luan $\left(\mathbb{D},{ }^{2}\right.$ Haibo Zhang $\mathbb{D}^{2}{ }^{2}$ Ruijing Zhang $\mathbb{D}^{2}{ }^{2}$ Jing Gao $(\mathbb{D})^{3}$ \\ Yuxia Wang $\mathbb{D}^{1},{ }^{1}$ Jia Li $\mathbb{D}^{1},{ }^{1}$ and Huiwen Ren $\mathbb{D}^{2}$ \\ ${ }^{1}$ Department of Endocrinology and Metabolism, The Fourth Affiliated Hospital of China Medical University, Shenyang, China \\ ${ }^{2}$ Advanced Institute for Medical Sciences, Dalian Medical University, Dalian, Liaoning, China \\ ${ }^{3}$ Department of Gerontology, Xin Hua Hospital, Shanghai Jiaotong University School of Medicine, Shanghai, China
}

Correspondence should be addressed to Huiwen Ren; rhwcmu@163.com

Received 22 October 2021; Revised 20 December 2021; Accepted 3 January 2022; Published 27 January 2022

Academic Editor: Yingqing Chen

Copyright (c) 2022 Che Bian et al. This is an open access article distributed under the Creative Commons Attribution License, which permits unrestricted use, distribution, and reproduction in any medium, provided the original work is properly cited.

\begin{abstract}
Aim. The study is aimed at verifying miR-154-5p and Smurf1 combination in glomerular mesangial cells regulating TGF $\beta 1 /$ Smad3 pathway-related protein ubiquitination in the model of diabetic rats renal tissues, primary mesangial cells, and cell lines. Methods. The diabetic SD rat model and high-glucose-cultured primary mesangial cells and cell lines were established. miR-154-5p mimic and inhibitor, Smurf1 siRNA, and TGF $\beta$ 1/Smad3 inhibitor (SB431542) were pretreated to make the TGF $\beta 1 /$ Smad3 pathway and ubiquitin changes. Fluorescence in situ hybridization was used for the miR-154-5p renal localization; molecular biological detection was adopted for cell proliferation, renal function, urine protein, and pathway proteins. After bioinformatics predicted binding sites, luciferase and Co-IP were used to detect miRNA and protein binding. Results. miR-154-5p was significantly increased and mainly concentrated in the glomerular of renal cortex in well-established diabetic rat renal tissues. Rno-miR-154-5p combined Rno-Smurf1 3' UTR, while Smurf1 combined Smad3 directly. Meanwhile, miR-154-5p regulates TGF $\beta 1 /$ Smad3-mediated cell proliferation via Smurf1 ubiquitination. Conclusion. miR-154$5 \mathrm{p}$ regulates the TGF $\beta 1 /$ Smads pathway through Smurf1 ubiquitination and promotes the fibrosis process of diabetic kidney disease.
\end{abstract}

\section{Introduction}

Diabetic kidney disease (DKD), formerly known as diabetic nephropathy $(\mathrm{DN})$, is one of the most common chronic microvascular complications of diabetes mellitus, leading to end-stage renal disease (ESRD) [1], involving various renal sections mainly of glomerulus [2], and regarding urinary albumin to creatinine ratio (UACR) as one of the effective noninvasive detection methods [3-5]. The TGF $\beta 1 /$ Smads pathway is a classic DKD way to regulate the proliferation and fibrosis of mesangial cells [6,7]. MicroRNA (miRNA) is a kind of noncoding RNA with the length of 18-25 highly conserved nucleic acids of which miR-154 is located in the miRNA-rich region of the $14 \mathrm{q} 32$ singlestranded chromosome in mammals [8], with one of the mature, miR-154-5p, indicating significant correlation with urine protein and fibrotic factors of diabetic patients in our previous studies $[9,10]$. However, the specific mechanism of miR-154-5p regulating DKD has not been studied. Therefore, the purpose of this study is to detect the expression of miR-154-5p in various models in vitro and in vivo on the basis of the successful establishment of diabetic rat model in previous studies $[11,12]$, and to explore the specific molecular mechanism of miR-154-5p regulating DKD in glomerular mesangial cells through bioinformatics prediction and verification.

\section{Materials and Methods}

2.1. Reagents. All the reagents were listed in Table 1. The siRNAs targeting Smurf1, miR-154-5p mimics, inhibitors, and plasmid vectors using psiCHECK 2.0 Vector System for the construction of target gene $3^{\prime}$ UTR, as well as their corresponding negative controls, were designed and 
TABLE 1: Information of reagents.

\begin{tabular}{|c|c|}
\hline Names & Information \\
\hline \multicolumn{2}{|l|}{ Treatment } \\
\hline Rno-miR-154-5p mimic forward & $5^{\prime}$ - UAG GUU AUC CGU GUU GCC UUC G -3', GenePharma \\
\hline Rno-miR-154-5p mimic reverse & $5^{\prime}$ - AAG GCA ACA CGG AUA ACC UAU U -3', GenePharma \\
\hline Rno-miR-154-5p inhibitor & $5^{\prime}$ - CGA AGG CAA CAC GGA UAA CCU A -3', GenePharma \\
\hline Rno-miR-negative control & $5^{\prime}$ - CAG UAC UUU UGU GUA GUA CAA - $3^{\prime}$, GenePharma \\
\hline Smurf1 siRNA forward sequence & $5^{\prime}$ - CAU AUC GCC AGA UCA UGA ATT -3', GenePharma \\
\hline Smurf1 siRNA reverse sequence & $5^{\prime}$ - UUC AUG AUC UGG CGA UAU GTT - $3^{\prime}$, GenePharma \\
\hline Negative control siRNA forward & $5^{\prime}$ - UUC UCC GAA CGU GUC ACG UTT -3', GenePharma \\
\hline Negative control siRNA reverse & $5^{\prime}$ - ACG UGA CAC GUU CGG AGA ATT - $3^{\prime}$, GenePharma \\
\hline TGF $\beta 1 /$ Smad3 inhibitor, SB431542 & \#14775, $10 \mathrm{nM}$ for $24 \mathrm{~h}$, dissolved in DMSO, Cell Signaling Technology \\
\hline \multicolumn{2}{|l|}{ Detection } \\
\hline Rno-miR-154-5p probe & $5^{\prime}$-FAM-CGA AGG CAA CAC GGA TAA CCT A-FAM-3' for FISH, GenePharma \\
\hline Rno-miR-154-5p primer forward & $5^{\prime}$ - CTG CCG TAG GTT ATC CGT G -3', GenePharma \\
\hline Rno-miR-154-5p primer reverse & $5^{\prime}$ - AGA GCA GGG TCC GAG GAT -3', GenePharma \\
\hline U6 primer forward & $5^{\prime}$ - CTC GCT TCG GCA GCA CA -3', GenePharma \\
\hline U6 primer reverse & $5^{\prime}$ - AAC GCT TCA CGA ATT TGC GT - $3^{\prime}$, GenePharma \\
\hline TGF $\beta 1$ primary antibody & Rabbit monoclonal antibody, ab215715, $44 \mathrm{kDa}, 1: 1000$ for WB. Abcam \\
\hline Smad3 primary antibody & Rabbit antibody, \#9523, $52 \mathrm{kDa}, 1: 1000$ for WB, $1: 100$ for IP, Cell Signaling Technology \\
\hline pSmad3 primary antibody & Rabbit antibody, \#9520, $52 \mathrm{kDa}, 1: 1000$ for WB, Cell Signaling Technology \\
\hline Smurf1 primary antibody & $\begin{array}{l}\text { Mouse monoclonal antibody, sc-100616, } 86 \mathrm{kDa}, 1: 200 \text { for } \mathrm{WB}, 2 \mu \mathrm{g} / 100 \mu \mathrm{g} \text { total } \\
\text { protein for IP, Santa Cruz Biotechnology }\end{array}$ \\
\hline Ubiquitin primary antibody & Rabbit antibody, \#3933, full bands, $1: 1000$ for WB, Cell Signaling Technology \\
\hline$\beta$-Actin primary antibody & Rabbit antibody, \#4970, $45 \mathrm{kDa}, 1: 1000$ for WB, Cell Signaling Technology \\
\hline IgG primary antibody & Rabbit antibody isotype control, \#3900, for IP, Cell Signaling Technology \\
\hline IgG primary antibody & Mouse antibody isotype control, \#5415, for IP, Cell Signaling Technology \\
\hline DAPI & For nucleus, \#4083, for IF, Cell Signaling Technology \\
\hline Anti-rabbit IgG & Anti-rabbit, \#3678, for WB, Cell Signaling Technology \\
\hline Anti-mouse IgG-HRP secondary antibody & Anti-mouse, \#7076, for WB, Cell Signaling Technology \\
\hline Anti-rabbit IgG-HRP secondary antibody & Anti-rabbit, \#7074, for WB, Cell Signaling Technology \\
\hline
\end{tabular}

synthesized by GenePharma, Shanghai, China. These reagents were transfected into cells using Lipofectamine ${ }^{\mathrm{TM}}$ 2000 Transfection Reagent (Invitrogen, USA) according to the manufacturer's instructions. The TGF $\beta 1 / \mathrm{Smad} 3$ pathway inhibitor, SB431542 (\#14775, $10 \mathrm{nmol} / \mathrm{l})$ was used to pretreat target cells as described in previous studies [13]. After the transfection and pretreatment, cells were collected and stored in liquid nitrogen for the follow-up experiments.

2.2. Animal Modeling. Sprague-Dawley (SD) rats (SPF grade, 7 weeks old, 180-220 g, purchased from Beijing Vital River Laboratory Animal Technology Co., Ltd.), were fed with free water and food at a constant temperature $\left(23 \pm 2{ }^{\circ} \mathrm{C}\right)$ and humidity (50-60\%), with a day/night cycle of $12 / 12 \mathrm{~h}$. The experiments were conducted from 9:00 a.m. to 11:00 a.m. daily to prevent circadian rhythm from influencing the results. All experimental protocols for animals have been approved by the Institutional Animal Care and Use Committee (IACUC) of China Medical University (Approval No. 2021115).
Rats were randomly assigned after one week adaptive feeding as the diabetic nephropathy group ( $\mathrm{DN}, n=10$ rats): fed with continuous high-fat diet (D12492, energy ratios of fat, carbohydrate, and protein as $60: 20: 20 \mathrm{kcal} \%$, total energy of $5.24 \mathrm{kcal} / \mathrm{gm}$, Research Diets, USA) and multiple injections with a low dose of streptozotocin (STZ, $35 \mathrm{mg}$ / $\mathrm{kg}$, cold $0.1 \mathrm{~m}$ sodium citrate buffer $\mathrm{pH} 4.5$, S0130, SigmaAldrich, USA) after 8 weeks high-fat diet induction and the normal control group (NC, $n=10$ rats): fed with control diet (D12450J, energy ratios of fat, carbohydrate, and protein as $10: 20: 20 \mathrm{kcal} \%$, total energy of $3.85 \mathrm{kcal} / \mathrm{gm}$, Research Diets, USA) and multiple injections with sodium citrate buffer as placebo. The specific modeling methods refer to our previous studies $[11,12]$.

2.3. Biochemical Detection. The intraperitoneal glucose tolerance test (IPGTT) and insulin release test (IRT) were performed for the detection of rat blood glucose and insulin levels. After $12-16 \mathrm{~h}$ starvation, rats were intraperitoneally injected with $2 \mathrm{~g} / \mathrm{kg}$ glucose, and blood glucose testing strips 
(OneTouch ${ }^{\circledR}$ Ultra, LIFESCAN, USA) were used for the detection of rat blood samples at $0,5,10,30,60$, and $120 \mathrm{~min}$, respectively. The enzyme-linked immunosorbent assay (ELISA) was used to measure rat insulin levels with the rat insulin ELISA kit (INS, CSB-E05070r, CUSABIO, USA). Homeostatic model of insulin resistance index (HOMA-IR) and insulin sensitivity index (ISI) were used to evaluate the insulin resistance and sensitivity, and GraphPad software was used to calculate the area under curve of glucose and insulin. When the metabolic cages were conducted, urine samples were collected and levels of urinary albumin with the rat microalbuminuria ELISA kit (MAU/ ALB, CSB-E12991r, CUSABIO, USA) were detected. Chemiluminescence was used to detect creatinine $(\mathrm{Cr})$ and blood urea nitrogen (BUN). Urinary albumin/creatine ratio (UACR, MAU/Cr ratio) is used for the detection of urinary protein.

2.4. Glomerular Isolation and Primary Mesangial Cell Culturing. Rat glomerulars were isolated from 2-3 rat renal tissues by dissecting renal cortex and medulla, digested with collagenase IV, subjected to serial sieving by cell strainer (70 and $100 \mu \mathrm{m}$, BD Falcon), and rinsed with Hanks' balanced salt solution (Thermo Scientific ${ }^{\mathrm{TM}}$ ). Then, the glomerular was cultured with 10\% FBS DMEM $\left(\mathrm{Gibco}^{\mathrm{TM}}\right)$ supplemented with $100 \mathrm{U} / \mathrm{ml}$ penicillin- $0.1 \mathrm{mg} / \mathrm{ml}$ streptomycin $\left(\mathrm{Gibco}^{\mathrm{TM}}\right)$ or stored for subsequent experiments. Primary mesangial cells (PMCs) climbed out of the glomerular after 2-3 days of culturing and were first passaged after 5-7 days and then were cultured with the normal culturing process. Cells in their $3^{\text {rd }}$ to $4^{\text {th }}$ generation at a ratio of $2 \times 10^{5}$ viable cells/ well in 6-well culture plates were used for subsequent experiments [14].

\subsection{Primary Proximal Tubular Epithelial Cell Culturing.} Mouse primary proximal tubular epithelial cells (PPTCs) were extracted from renal tissues of 4-6 mice by dissecting renal cortex as well as inner and outer medulla according to the previous literature [15]. Then, the cortex and outer medulla were digested with collagenase IV, subjected to serial sieving by cell strainer ( $40 \mu \mathrm{m}, \mathrm{BD}$ Falcon), rinsed with Hanks' balanced salt solution (Thermo Scientific ${ }^{\mathrm{TM}}$ ), layered with Percoll ${ }^{\circledR}$ (Sigma-Aldrich), and cultured with $10 \%$ FBS DMEM/F12 $\left(\right.$ Gibco $\left.^{\mathrm{TM}}\right)$ supplemented with insulin-transferrin-sodium selenite media supplement (Sigma-Aldrich), $1 \mathrm{mM}$ hydrocortisone (MedChemExpress $\left.^{\circledR}\right), \quad 50 \mathrm{mM}$ vitamin C (MedChemExpress $\left.{ }^{\circledR}\right)$, and $100 \mathrm{U} / \mathrm{ml}$ penicillin $-0.1 \mathrm{mg} / \mathrm{ml}$ streptomycin $\left(\mathrm{Gibco}^{\mathrm{TM}}\right)$. Cells at a ratio of $2 \times 10^{5}$ viable cells/well in 6 -well culture plates were used for subsequent experiments.

2.6. Cell Line Culturing and Treatment. Rat mesangial cells (RMCs, CRL-2573 ${ }^{\mathrm{TM}}$ ) and 293T cells (293T/17 or HEK 293T/17, CRL-1126 ${ }^{\mathrm{TM}}$ ) were purchased from American Type Culture Collection (ATCC ${ }^{\circledR}$ ) and cultured with Dulbecco's modified Eagle's medium (DMEM) containing 10\% fetal bovine serum (FBS, North American Source, Gibco) at $37^{\circ} \mathrm{C}$ with saturated humidity in $5 \% \mathrm{CO}_{2}$ atmosphere. Cells in their $5^{\text {th }}$ to $9^{\text {th }}$ generation of logarithmic growth phase were inoculated into $25 \mathrm{~cm}^{2}$ culture flasks at a ratio of $1 \times$ $10^{6} /$ flask or 6 -well tissue culture plates of $5 \times 10^{5} /$ well. After synchronization via starvation in Opti-MEM (Gibco, USA) for $24 \mathrm{~h}$ and confluency reached $70-80 \%$, cells were cultured with normal glucose (NG, $5.5 \mathrm{mmol} / \mathrm{l} \mathrm{D}$-glucose), high mannitol (HM, $5.5 \mathrm{mmol} / \mathrm{l} \mathrm{D}$-glucose and $24.5 \mathrm{mmol} / \mathrm{l} \mathrm{manni-}$ tol), and high glucose (HG, $30 \mathrm{mmol} / \mathrm{l}$ D-glucose), respectively, for $24 \mathrm{~h}$ and were collected and stored at $-196^{\circ} \mathrm{C}$ for the follow-up experiments.

2.7. Luciferase Reporter Assay. After using 293T validation, RMCs were inoculated into 24 -well plates of $5 \times 10^{5}$ cells/ well beforehand and cotransfected with miR-154-5p mimic, inhibitor, pmirGLO-Smurf1-3' UTR-WT or pmirGLOSmurf1-3' UTR-MUT reporter plasmids accordingly. After $24 \mathrm{~h}$ posttransfection, cells were lysed using passive lysis buffer (Promega) and the luciferase activity was measured with the Dual-Luciferase Reporter Assay System (Promega) and normalized to Renilla luciferase activity, respectively. Experiments were performed in triplicate.

2.8. Fluorescence In Situ Hybridization (FISH). FISH assays were performed using fluorescent in situ hybridization kit (Servicebio, China) according to the protocol. FAMdouble-labeled miR-154-5p probe were designed and synthesized by Servicebio (China). Tissues were first fixed in $4 \%$ formaldehyde for $15 \mathrm{~min}$, then permeabilized in PBS containing $0.5 \%$ Triton $\mathrm{X}-100$ at $4^{\circ} \mathrm{C}$ for $30 \mathrm{~min}$, and prehybridized at $37^{\circ} \mathrm{C}$ for $30 \mathrm{~min}$ in prehybridization solution. After that, probes were added in the hybridization solution and incubated with the tissue sections at $37^{\circ} \mathrm{C}$ overnight in the dark. The next day, the tissue sections were counterstained with DAPI for nuclear and imaged and then measured by a digital microscope application, CaseViewer (3DHISTECH Ltd.), for supporting histopathological diagnostic workflow and the microscope examination process in bioscience.

2.9. miRNA Real-Time PCR Assay. The miRcute miRNA Isolation Kit (DP501, Tiangen Biotech) was used for the isolation of miRNA and miRcute miRNA First-Strand cDNA Synthesis Kit (KR201, Tiangen Biotech) for the reverse transcription from miRNA into cDNA. The reverse transcriptional reaction process was $26^{\circ} \mathrm{C}$ for $20 \mathrm{~min}, 42^{\circ} \mathrm{C}$ for $40 \mathrm{~min}$, and $85^{\circ} \mathrm{C}$ for $10 \mathrm{~min}$ holding. The miRcute miRNA qPCR Detection Kit (SYBR Green, FP401, Tiangen Biotech) was used to amplify the PCR reaction via Thermal Cycler Dice Real Time System (TaKaRa). The primer sequences of rno-miR-154-5p (designed and synthesized by GenePharma) were shown in Table 1 . The PCR reaction system was $20 \mu \mathrm{l}$ containing $2 \mu \mathrm{l} \mathrm{cDNA}$ with the response procedures: after initial degeneration at $95^{\circ} \mathrm{C}$ for $3 \mathrm{~min}$, degeneration at $95^{\circ} \mathrm{C}$ for $12 \mathrm{~s}$, annealing at $62^{\circ} \mathrm{C}$ for $40 \mathrm{~s}$, and extension at $72^{\circ} \mathrm{C}$ for $30 \mathrm{~s}$ with 40 circles. The $\mathrm{CT}$ value was read for dissolution curve analysis with U6 snRNA (Tiangen Biotech) for internal standardization, while $2^{-\Delta \Delta \mathrm{CT}}$ method was used to calculate the relative expression. 
2.10. Co-immunoprecipitation. The EZ Magna RNA immunoprecipitation Kit (Millipore, USA) was used following the guidelines. Briefly, RMCs were lysed in RIP lysis buffer. Magnetic beads were preincubated with antibodies for $30 \mathrm{~min}$ at room temperature and the cell lysates were immunoprecipitated with beads for $6 \mathrm{~h}$ at $4^{\circ} \mathrm{C}$. Then, protein was purified and detected by western blotting. Antibody information of Smurf1 and Smad3 is listed in Table 1.

2.11. Western Blotting. Protein samples were extracted with the lysis buffer containing the protease inhibitor, while total protein content was determined by the Pierce ${ }^{\mathrm{TM}}$ BCA Protein Assay Kit (Thermo Scientific ${ }^{\mathrm{TM}}$, USA). The SDS-PAGE electrophoresis was conducted after protein denaturation, and then, bands were transferred onto PVDF membranes according to a certain time. The membrane was blocked by $5 \%$ bovine serum albumin (BSA, Sigma Aldrich, USA) for $2 \mathrm{~h}$ and incubated with the corresponding concentration of primary antibodies (shown in Table 1) at $4^{\circ} \mathrm{C}$ overnight. After incubation of secondary antibodies at room temperature for $2 \mathrm{~h}$, the Pierce ${ }^{\mathrm{TM}}$ ECL Western Blotting Substrate was used for membrane imaging via the imaging system (MicroChemi 4.2, Israel) with the detection of grey values by ImageJ 1.52i Java 1.8.0_172 (64-bit, National Institutes of Health, USA).

2.12. Cell Proliferation Assay. Cell samples were digested by trypsin and made into cell suspension. Appropriate cell density $\left(5 \times 10^{3}-2 \times 10^{4}\right.$ cells/well $)$ was inoculated on a 96-well plate for 24-72 h. Cell Counting Kit-8 (CCK-8, DOJINDO, Japan) Cell Proliferation and Cytotoxicity Assay Kit (Roche, USA) were used after cell adherence. CCK- 8 detection solutions were added to 96 -well plate for $2-4 \mathrm{~h}$, while the absorbance of CCK- 8 was read at $450 \mathrm{~nm}$ and $630 \mathrm{~nm}$ as reference by a full wavelength microarray (BioTek Power Wave XS).

2.13. Bioinformatics Analysis. Potential target mRNAs of miR-154-5p were predicted by the computer algorithm RNA22 V2 (https://cm.jefferson.edu/rna22/Interactive/). The mature miRNA sequences used by RNA22 V2 were downloaded from miRBase (http://www.mirbase.org/). Protein interaction analysis was performed using inBio_Map (v2016_09_12), IntAct Molecular Interaction Database, and STRING (version 11.0). All protein information was extracted from UniProtKB/Swiss-Prot database, and UbPred software was used to randomly predict the potential ubiquitination sites of proteins in the forest model. UbiBrowser and NetPath/NetSlim databases were used to verify ubiquitin ligase recognition characteristics and to locate known ubiquitin binding sites.

2.14. Statistical Analysis. The experiment was repeated more than three times under the same experimental conditions, and obtained data were statistically analyzed by SPS 20.0 software. After testing each variable of normal distribution, normal distribution of measurement data was expressed with mean \pm standard deviation $(\bar{x} \pm s)$, while nonnormal distribution data with median (interquartile range). Students' $t$-test (between two groups) and one-way analysis of variance (ANOVA, among three or more groups) were used for the comparison followed by multiple comparison using the least square method $t$-test for homogeneity of variance and Tamhane's T2 test for heterogeneity of variance. $P<$ 0.05 was considered of statistically significance with two tails.

\section{Results}

3.1. Changes of miR-154-5p and Pathway in Animal Models. We successfully established the diabetic rat model induced by high-fat diet and STZ based on previous studies. Physiological indexes indicated that the IPGTT overall level curve, HbA1c, area under curve of glucose, and HOMAIR significantly increased, while the area under curve of insulin, area under curve of insulin/glucose ratio, and ISI significantly decreased, but the IRT curve does not appear to have an obvious peak in the DN group. In addition, DBP and SBP had no significant changes, excluding the influence of blood pressure. Renal function (BUN and $\mathrm{Cr}$ ) and urinary protein (UACR) were significantly increased (Figure 1).

FISH results showed that the relative expression of miR154-5p was significantly increased, and the localization of miR-154-5p was mainly concentrated in the renal cortex of well-established diabetic rat renal tissues. The enlarged graph showed that the expression of miR-154-5p was significantly enriched in the glomerular region (Figure 2(a)). To verify the results of the localization experiment, we performed fine anatomy of renal tissue. Real-time PCR results showed that the levels of the total renal tissues and cortex were significantly increased, while there were no significant changes in the inner and outer medulla (Figure 2(b)). The microdissection of the cortex and outer and inner medullary was seen in Figure 2(c). The results of the both experiments were consistent, indicating highly expression of miR-154-5p in the glomerulus. Moreover, pathway proteins (TGF $\beta 1$ and pSmad3/Smad3) were significantly increased in the diabetic renal tissues (Figure $2(\mathrm{~d})$ ).

3.2. Changes of miR-154-5p and Pathway in Primary Cell and Cell Lines. We successfully isolated rat glomerulus (Figure 3(a)), and on the basis of successful culturing PMCs and PPTCs (Figure 3(b)), it was found that the expression of miR-154-5p in PMCs was significantly increased under high-glucose culturing, while with no changes in PPTCs (Figure 3(c)). Further study on the expression of miR-154$5 p$ showed that the relative expression of miR-154-5p in mesangial cell lines, RMCs, under high-glucose culturing also showed a time-dependent increase and tended to be stable after high-glucose culturing for $24 \mathrm{~h}$ (Figure 3(d)). Compared with the NG group, the area under curve of CCK-8 $\mathrm{OD}$ at $450 \mathrm{~nm}$ and the levels of fibrotic factors in the NG group were significantly increased (Figures 3(e) and 3(f)). In addition, there were no significant changes in the above results of the HM group, excluding the effect of osmotic pressure. TGF $\beta 1$ and $\mathrm{pSmad} 3 / \mathrm{Smad} 3$ were both significantly increased in successfully established RMCs with a high-glucose culture (Figure 3(g)). 


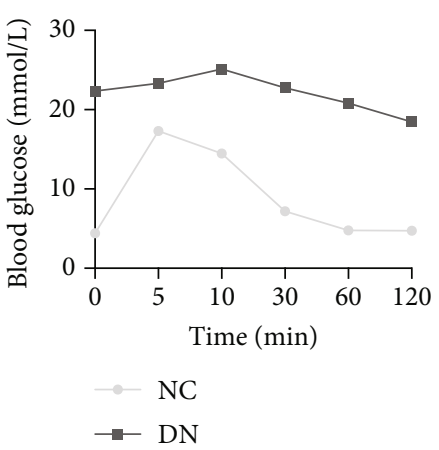

(a)

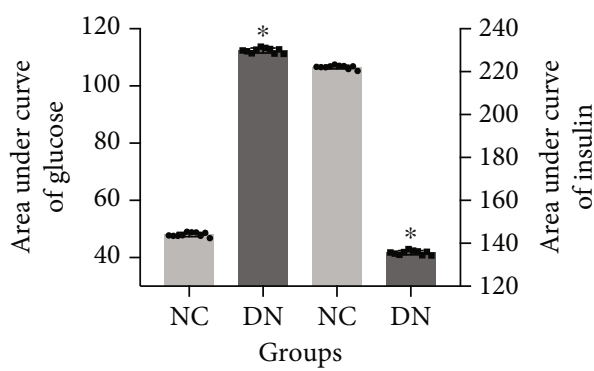

(d)

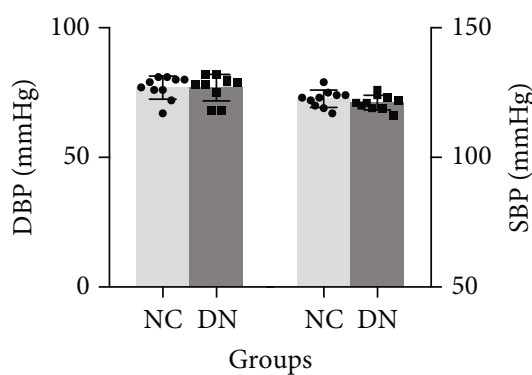

(g)

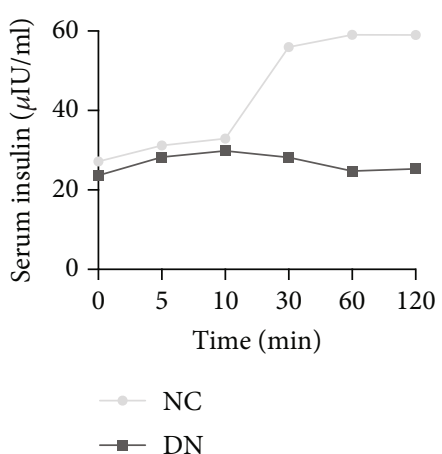

(b)

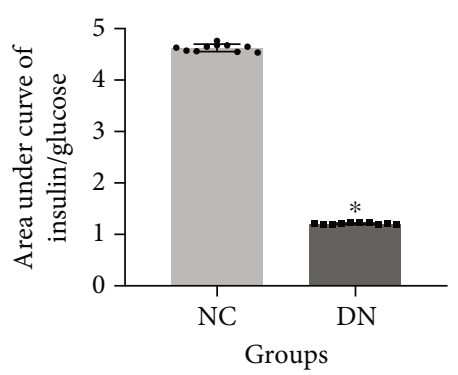

(e)

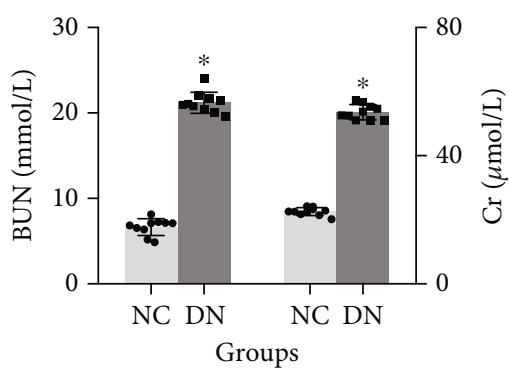

(h)

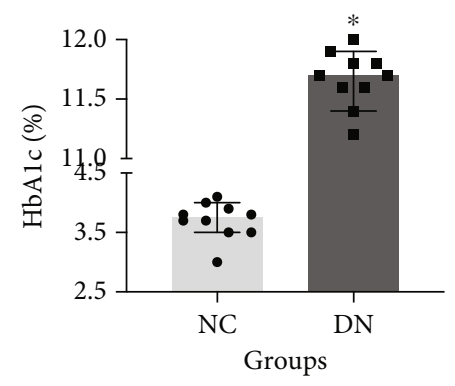

(c)

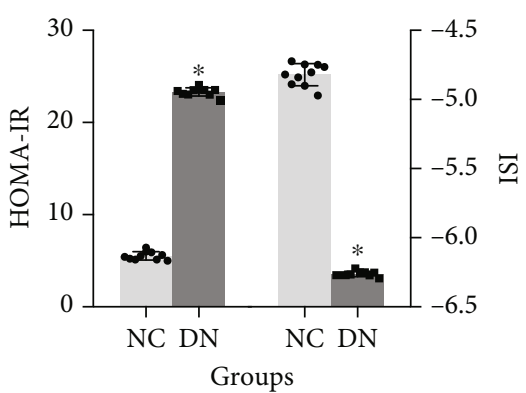

(f)

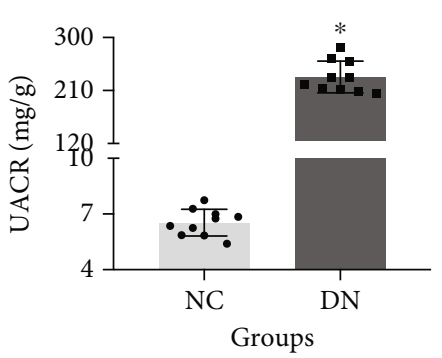

(i)

Figure 1: Physiological indexes in diabetic rats. Time-dependent curve in intraperitoneal glucose tolerance test (a) and insulin release test (b), HbAlc levels (c), area under curve of blood glucose (d left) and insulin (d right), area under curve ratio of insulin to blood glucose (e), HOMA-IR and ISI (f), DBP/SBP (g), renal function (h), and UACR (i). NC: normal control, DN: diabetic nephropathy. ${ }^{*}$ vs. NC, $P<0.05$. $n=10$ rats/group.

3.3. The Role of miR-154-5p Regulating the TGF $\beta 1 /$ Smads Pathway. After the construction of the miR-154-5p mimic and inhibitor transfection, the expression of miR-154-5p proved that the transfection model was successfully constructed (Figure 4(a)). TGF $\beta 1$ and $\mathrm{pSmad} 3 / \mathrm{Smad} 3$ were significantly increased, and CCK- 8 showed abnormal proliferation in normal- and high-glucose-cultured RMCs with the miR-154-5p mimic treatment. On the contrary, TGF $\beta 1$ and $\mathrm{pSmad} 3 / \mathrm{Smad} 3$ were significantly decreased in RMCs treated with the miR-154-5p inhibitor, and cell proliferation was decreased (Figures $4(\mathrm{~b})-4(\mathrm{~d})$ ).

3.4. Verification of miR-154-5p Target Gene, Smurf1. To further investigate the function of miR-154-5p, we used the RNA22 V2 computer algorithm to predict the target genes of human and rat miR-154-5p, and the mature miRNA sequences were downloaded from miRBase. The results of bioinformatics analysis showed that there was a target gene, Smurf1, binding with miR-154-5p in humans and rats with multiple binding sites (Figure S1), suggesting that humans and rats had highly similar binding patterns. Changes of Smurf1 were observed in renal tissues of diabetic rats and in vitro models cultured with high glucose (Figures 5(a) and 5(b)). After that, miR-154-5p inhibitor, Smurf1 siRNA and TGF $\beta 1 /$ Smads pathway inhibitor were pretreated into RMCs cultured with high glucose, respectively. Levels of ubiquitin-related molecule, Smurf1, were significantly decreased in the Smurf1 siRNA group and significantly increased in the miR-154-5p inhibitor group. Smurf1 in the TGF $\beta 1 /$ Smads pathway inhibitor group was reduced compared with the miR-154-5p inhibitor group. The expression of TGF $\beta 1$ and $\mathrm{pSmad} 3 / \mathrm{Smad} 3$ was significantly 

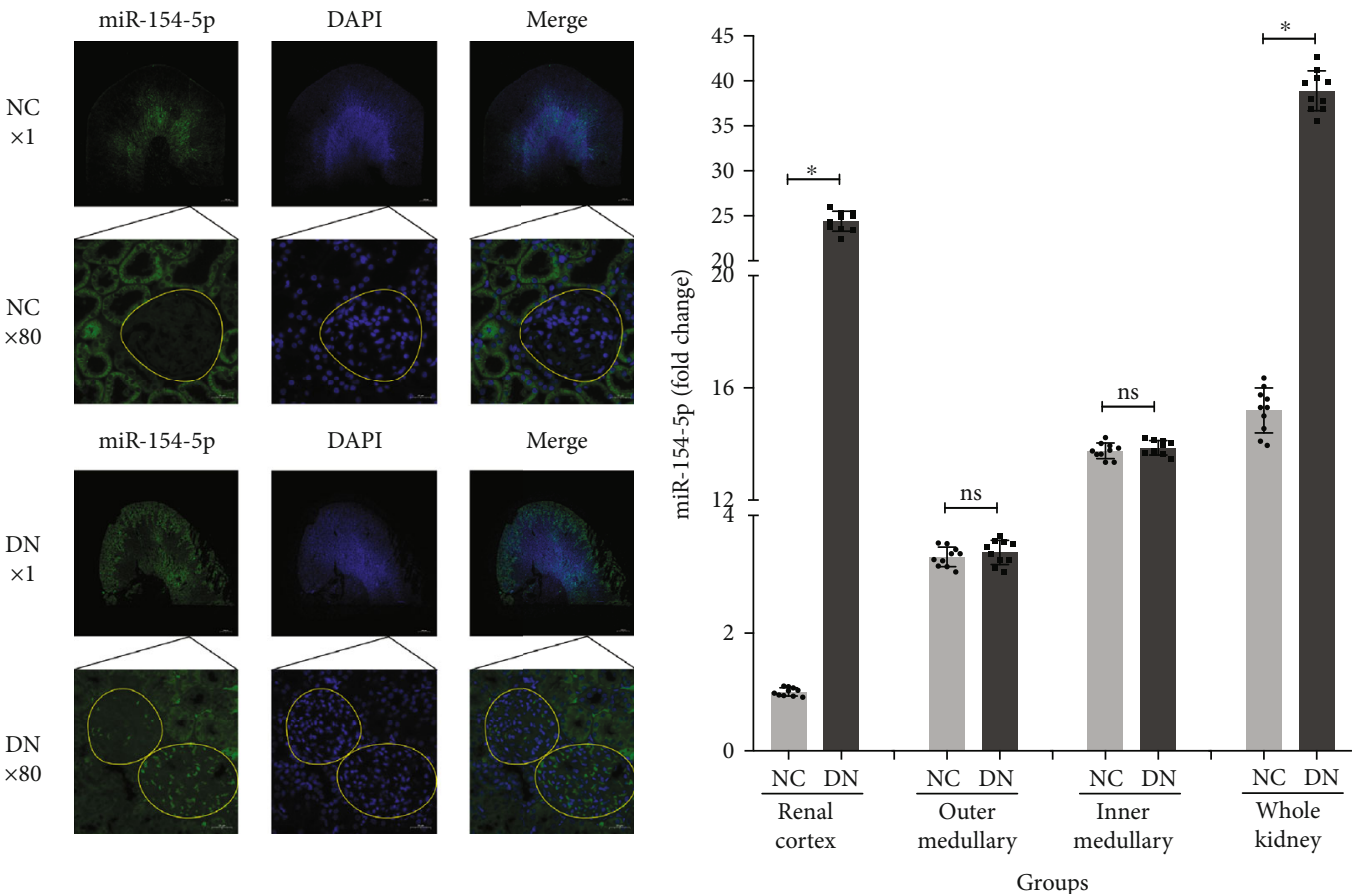

(a)
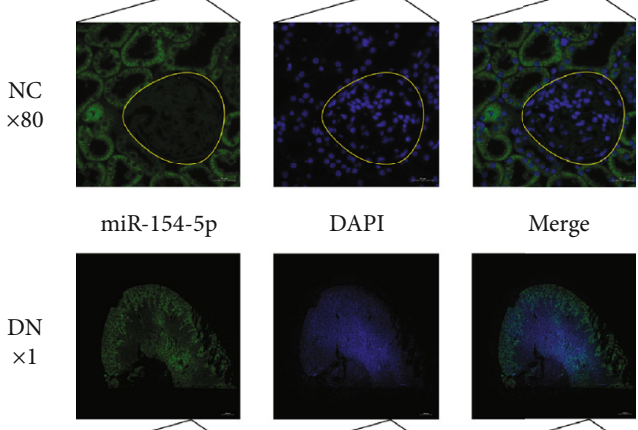

DAPI
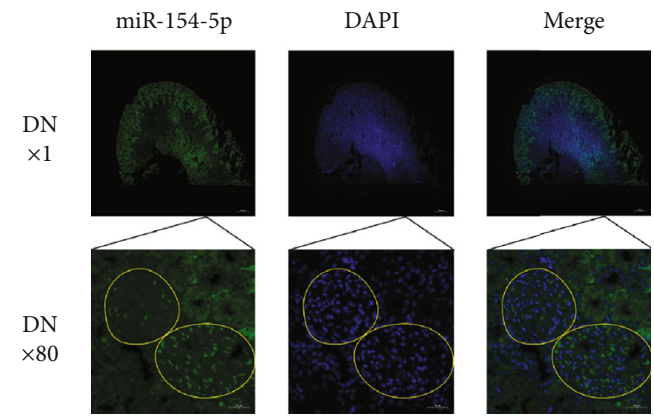

(b)

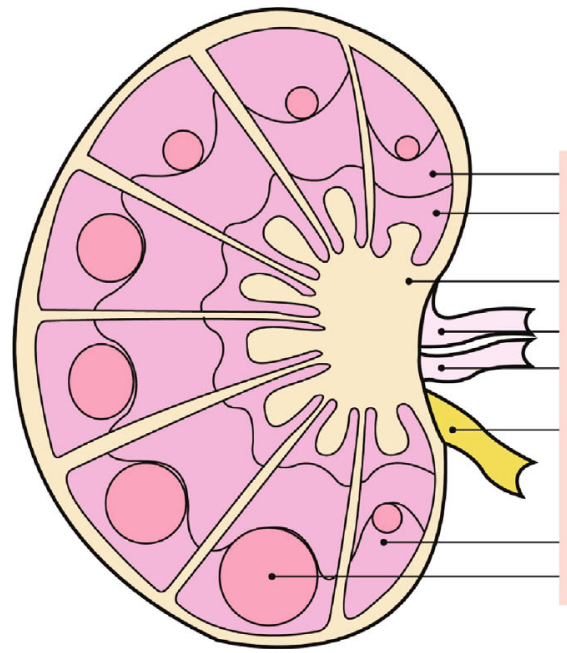

Outer medullary Inner medullary

Renal papillae

Renal artery

Renal vein

Ureter

Renal cortex Glomerular

(c)
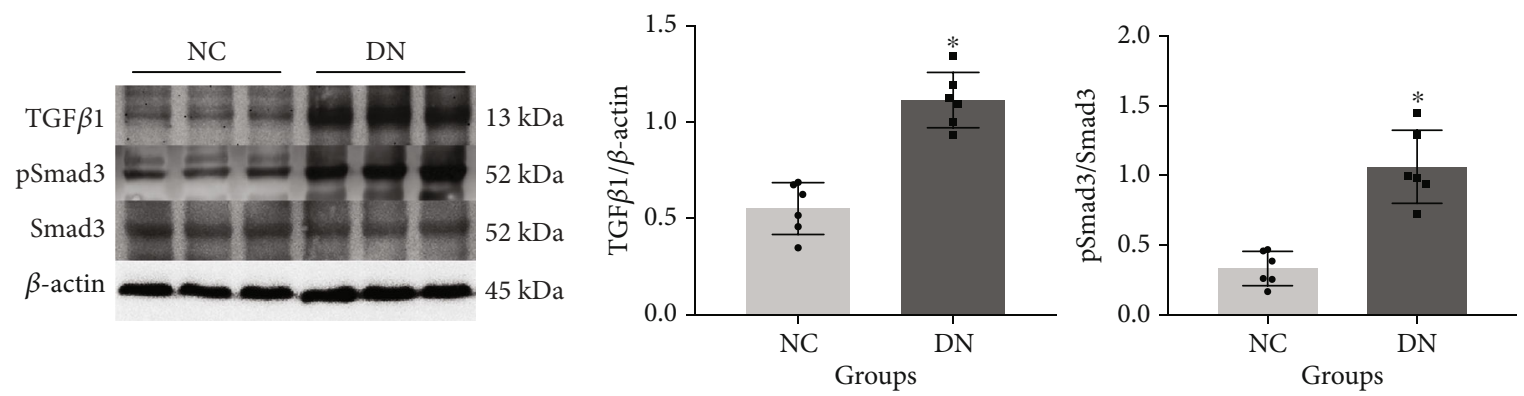

(d)

FIgURE 2: Expression of miR-154-5p in renal tissues. FISH detection for miR-154-5p localization in the kidney; significant enrichment of miR-154-5p in the cortical region of diabetic rats, in particular, glomerular (a). miR-154-5p in the cortex, outer medullary, inner medullary, and total kidney; homogenized semiquantified according to the NC group in the renal cortex (b). Microanatomy of the kidney (c). Protein levels in the whole kidney (d). NC: normal control; DN: diabetic nephropathy. Yellow circles indicate the glomerular. ${ }^{*}$ vs. NC, $P<0.05$; ns: vs. NC, $P>0.05 . n=6$ samples/group. 
Glomerular

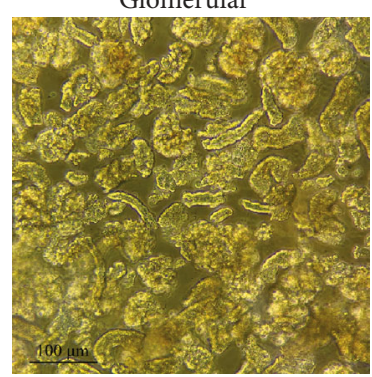

(a)

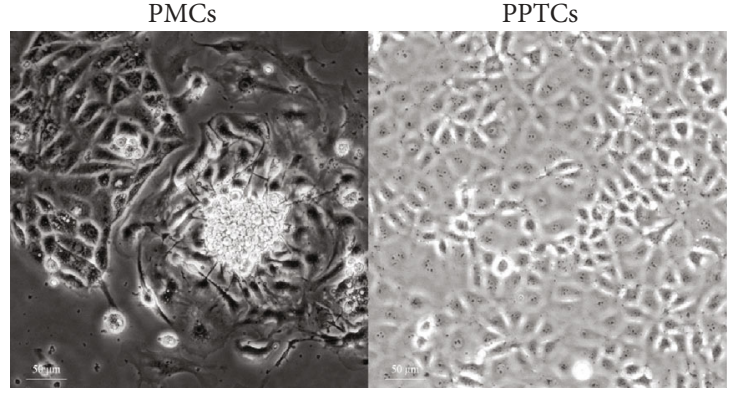

(b)

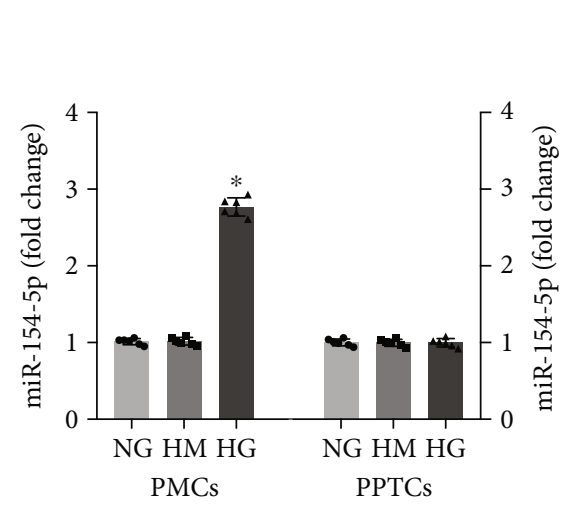

(c)

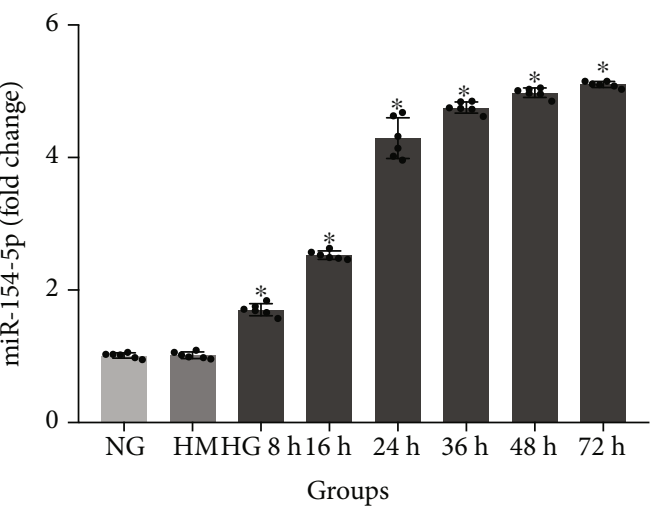

(d)

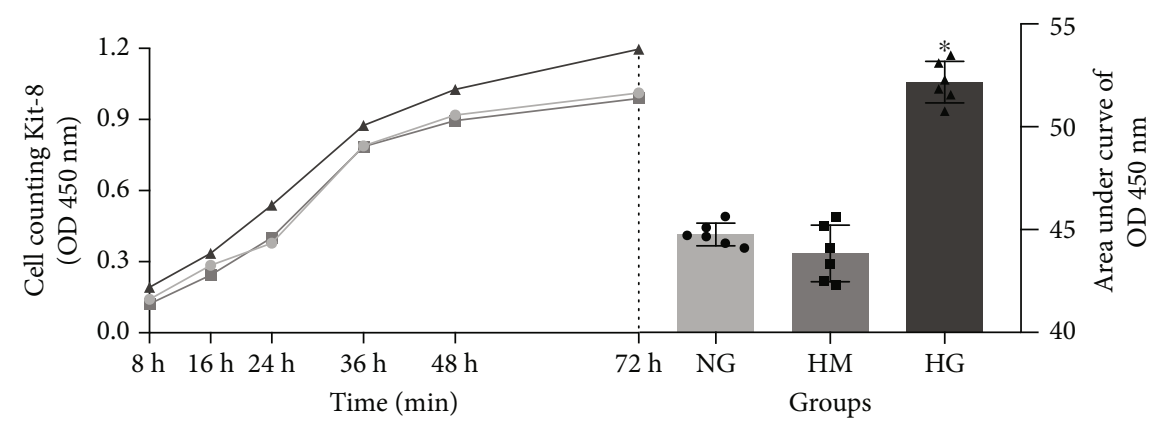

$$
\begin{aligned}
& \rightarrow \mathrm{NG} \\
& \rightarrow \mathrm{HM} \\
& \longleftarrow \mathrm{HG}
\end{aligned}
$$

(e)
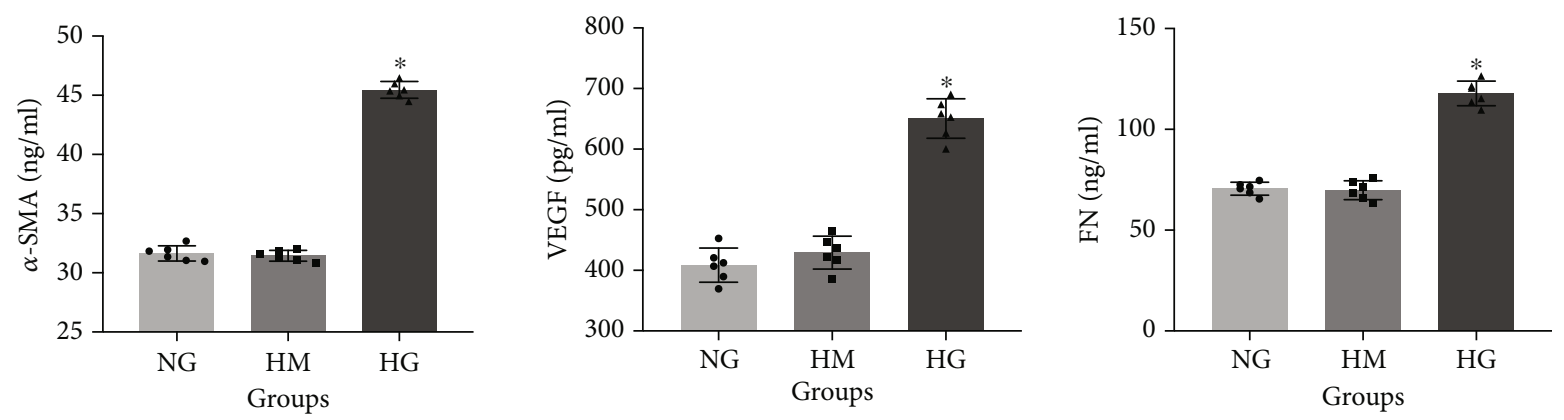

(f)

Figure 3: Continued. 

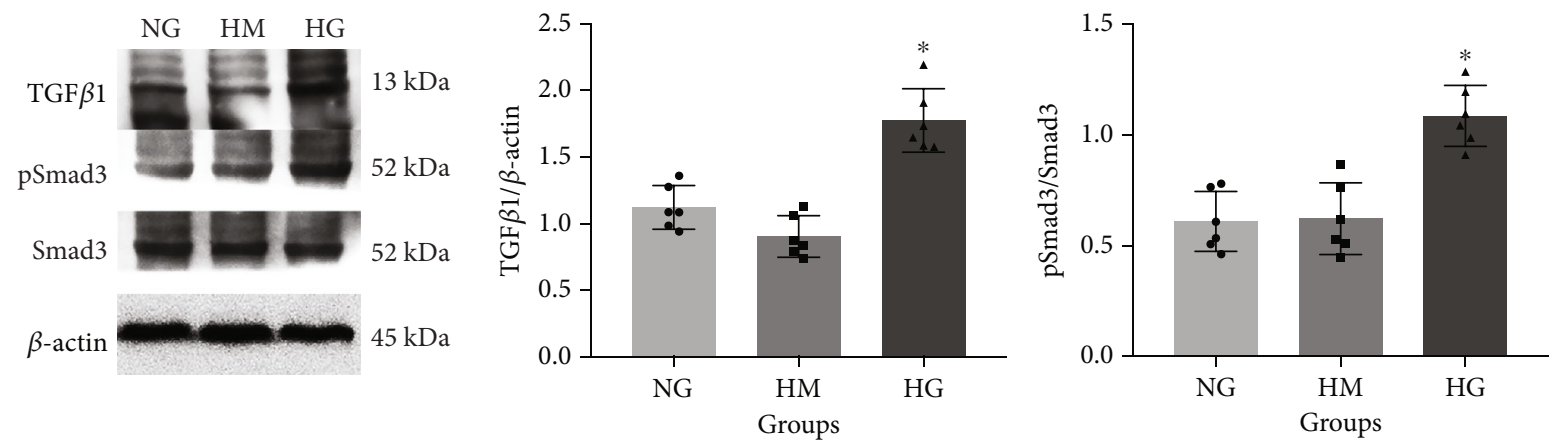

(g)

Figure 3: Expression of miR-154-5p in primary cells and cell lines. Rat glomerular isolation (a). Morphology extraction of primary mesangial cells (PMCs) and primary proximal tubular cells (PPTCs, b) with scale bar $50 \mu \mathrm{m}$. miR-154-5p in high-glucose-cultured PMCs and PPTCs (c) as well as RMCs at different time points (d). CCK-8 cell proliferation in RMCs at different time points (e). Levels of VEGF, $\alpha$-SMA, and FN in RMC supernatant (f). Protein expression in high-glucose-cultured RMCs (g). NG: normal glucose; HM: high mannitol; HG: high glucose. *v. NC, $P<0.05 . n=6$ samples/group.

decreased in the miR-154-5p inhibitor and TGF $\beta 1 /$ Smads pathway inhibitor groups and significantly increased in the Smurf1 siRNA group (Figure 5(c)).

3.5. Smurf1 Regulates Ubiquitination through Smad3. As a member of HECT family with E3 ubiquitin ligases, Smurf1 is a key enzyme that determines substrate specificity in the ubiquitin-modifying pathway. It can recognize ubiquitinated protein substrates and selectively regulate the degradation process of effector molecules Smads ubiquitination. The mechanism was seen in Figure S2A. Based on the analysis of known ubiquitination binding sites in the NetPath/NetSlim database, it was found that the known ubiquitination binding sites for Smurf1 were RhoA, Smad7, and TRI (Figure S2B). Smurf1 interacts with TGF $\beta 1$ receptors, Smads, RhoA, Smurf2, and other Smurf1 proteins in inBio_Map (v2016_09_12) and IntAct Molecular Int analysis (Figure S3A). UbiBrowser database verified ubiquitin ligase recognition characteristics and found that Smurfl had high ubiquitin binding ability to Smad2, Smad3, Smad4, and Smurf2, respectively (Figure S3B), and Smad3 had potential sites for binding to the C2 and HECT regions of Smurfl (MH1: position 31-131, length 101; MH2: position 226-403, length 178), suggesting that Smurf1 and Smad3 may have a potential ubiquitination binding mode. Moreover, Smurf1 and Smad3 structures of humans and rats collected from the UniProtKB/Swiss-Prot database were compared. Sequence alignment results showed that the corresponding sequences in $\mathrm{C} 2$ and HECT regions of Smurf1 as well as the $\mathrm{MH} 1$ and $\mathrm{MH} 2$ regions of Smad3 were exactly the same in humans and rats (Figure S3C), indicating highly similar binding patterns in both humans and rats.

To verify the regulatory and binding effects of Smurf1 and Smad3, RMCs were treated with Smurf1 siRNA and TGF $\beta 1 /$ Smad3 inhibitor, SB431542. Smad3 was found to restore Smurf1-induced $\mathrm{pSmad} 3 / \mathrm{Smad} 3$ and ubiquitin expression (Figure 6(b)) as well as the abnormal cell proliferation detected by CCK-8 (Figure 6(a)). In addition, Co-IP validation found direct binding sites between Smurf1 and Smad3 (Figure 6(c)).
3.6. miR-154-5p Influences Smurf1-Mediated Ubiquitination of Smad3. To further verify the regulation and binding of miR-154-5p and Smurf1, RMCs were pretreated with the miR-154-5p inhibitor and Smurf1 siRNA, and the detection found that Smurf1 can reverse the regulation of miR-154-5p on $\mathrm{pSmad} 3 / \mathrm{Smad} 3$ and ubiquitin expressions (Figures 7 (a) and $7(\mathrm{c}))$ as well as the abnormal cell proliferation detected by CCK-8 (Figure 7(b)). In addition, Rno-miR-154-5p and Rno-Smurf1 $3^{\prime}$ UTR were able to bind directly in the predictive analysis, and luciferase validation showed that RnomiR-154-5p and Rno-Smurf1 $3^{\prime}$ UTR produced direct binding (Figure 7(d)).

\section{Discussion}

Type 2 diabetes mellitus (T2DM) is a long-term metabolic disorder characterized by hyperglycemia, insulin resistance, and relative deficiency of insulin [16]. Diabetic kidney disease (DKD) is one of the most common chronic microvascular complications of T2DM, which can lead to end-stage renal disease (ESRD) and even renal failure $[1,17,18]$ and increased death caused by cardiovascular events [19], which bring heavy economic burden to the society and family. The characteristic clinical manifestation of DKD is continuous and has slow development of proteinuria. In clinical practice, in addition to invasive renal biopsy as the gold standard for diagnosis, noninvasive urinary albumin to creatinine ratio (UACR) and glomerular filter rate detection are also used as the basis for diagnosis and classification [3-5]. DKD lesions can involve all parts of the kidney, including abnormal proliferation of glomerular mesangial cells, thickening of basement membrane, glomerular sclerosis, and podocyte loss in early stage, while renal tubular basement membrane thickening, tubular atrophy, renal interstitial inflammatory infiltration, and renal interstitial fibrosis were observed in the later stage [2]. Among them, abnormal proliferation of mesangial cells, renal interstitial fibrosis, and podocyte injury are important pathological processes of fibrosis, which run through the whole process of DKD 

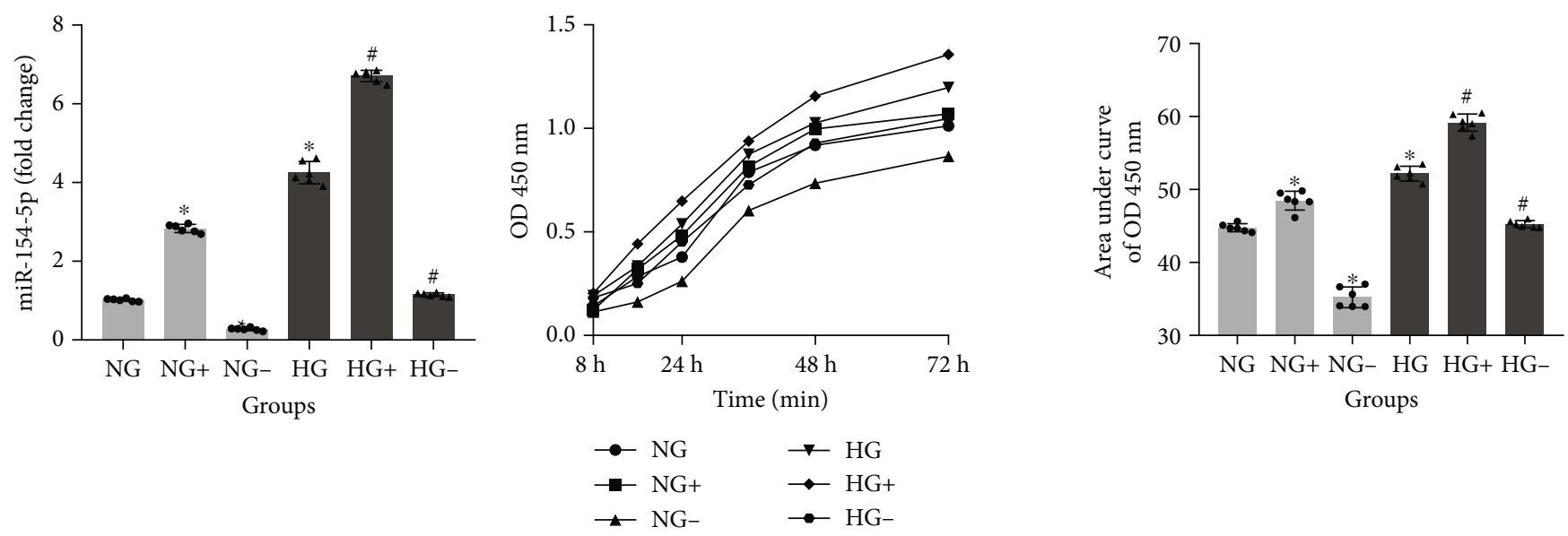

(a)
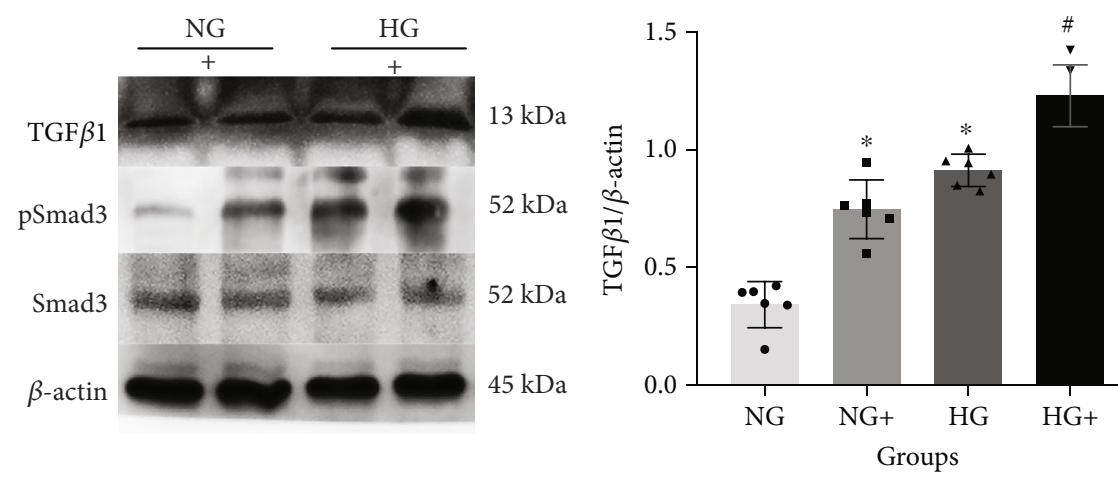

(b)

(c)
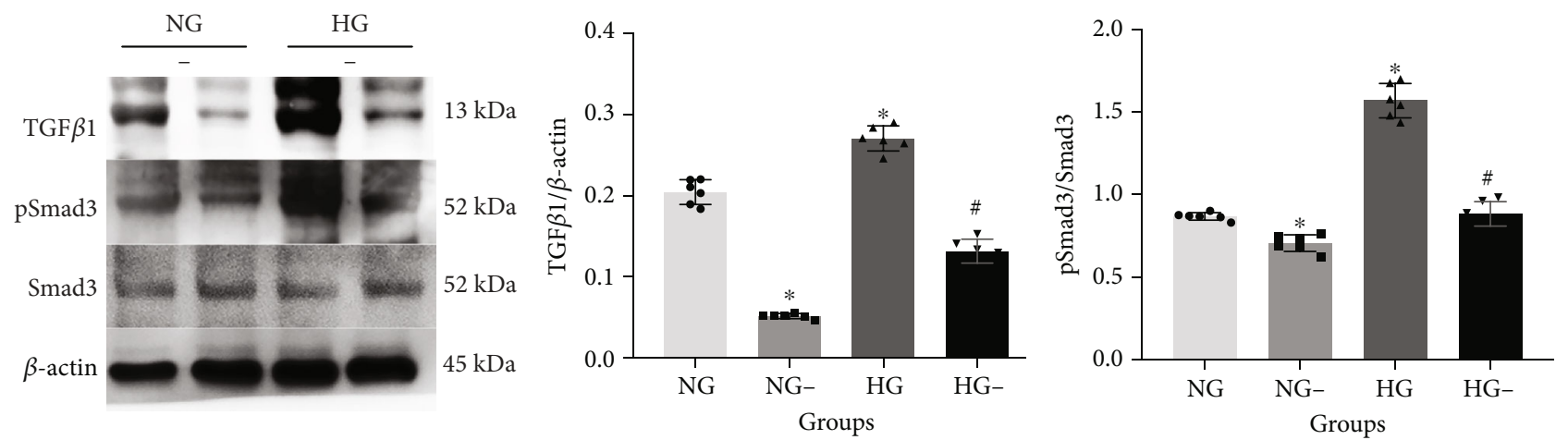

(d)

FIGURE 4: The role of miR-154-5p regulating the TGF $\beta 1 /$ Smads pathway. Levels of miR-154-5p (a), CCK-8 cell proliferation (b), and protein expression levels (c, d) in RMCs with miR-154-5p mimic and inhibitor. NG: normal glucose; NG+ or - : normal glucose with mimic or inhibitor; HG: high glucose, HG+ or - : high glucose with mimic or inhibitor. ${ }^{*}$ vs $\mathrm{NG}, P<0.05$; ${ }^{*}$ vs. HG, $P<0.05 . n=6$ samples/group.

disease, and have become an important biomarker to evaluate the progress of DKD.

Fibrosis is the core of high morbidity and mortality associated with $\mathrm{DKD}$, and its production is mainly the result of multiple factors such as high glomerular filtration, increased advanced glycation end products, and reactive oxygen species, as well as the activation of renin-angiotensin-aldosterone system. Abnormal proliferation of rat mesangial cells (RMCs) is an important pathological change in the early stage of DKD fibrosis, and RMCs cultured in high glucose are a classic model for the study of DKD $[20,21]$. The intracellular molecular pathways are believed related to mesangial cell proliferation and fibrosis including the activation of renin-angiotensin system, transforming growth factor $\beta 1$ (TGF $\beta 1$ ), monocyte chemotactic protein-1, connective tissue growth factor (CTGF), and fibronectin (FN), etc. [22-25], which can effectively assess the extent of renal injury and timely guide the clinical treatment of DKD [26-29].

MicroRNAs (miRNAs) are highly conserved noncoding RNAs with a length of 18-25 nucleic acids that regulate gene expression through incomplete complementary base sequences at the $3^{\prime}$ terminal untranslated region (UTR) of the target 


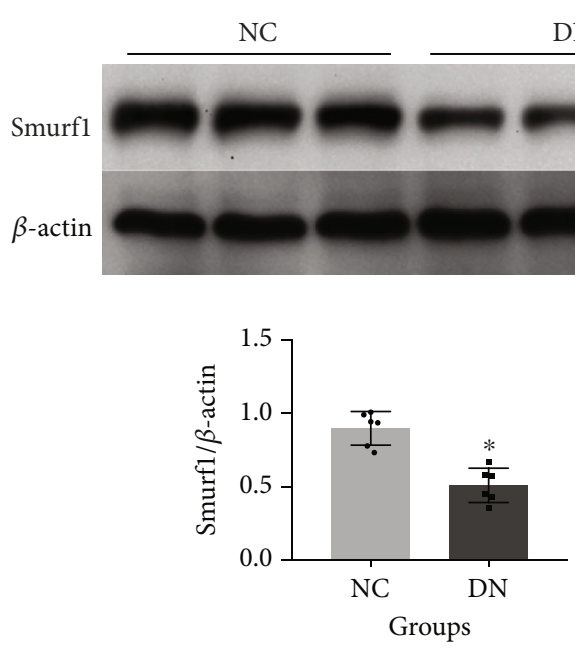

(a)

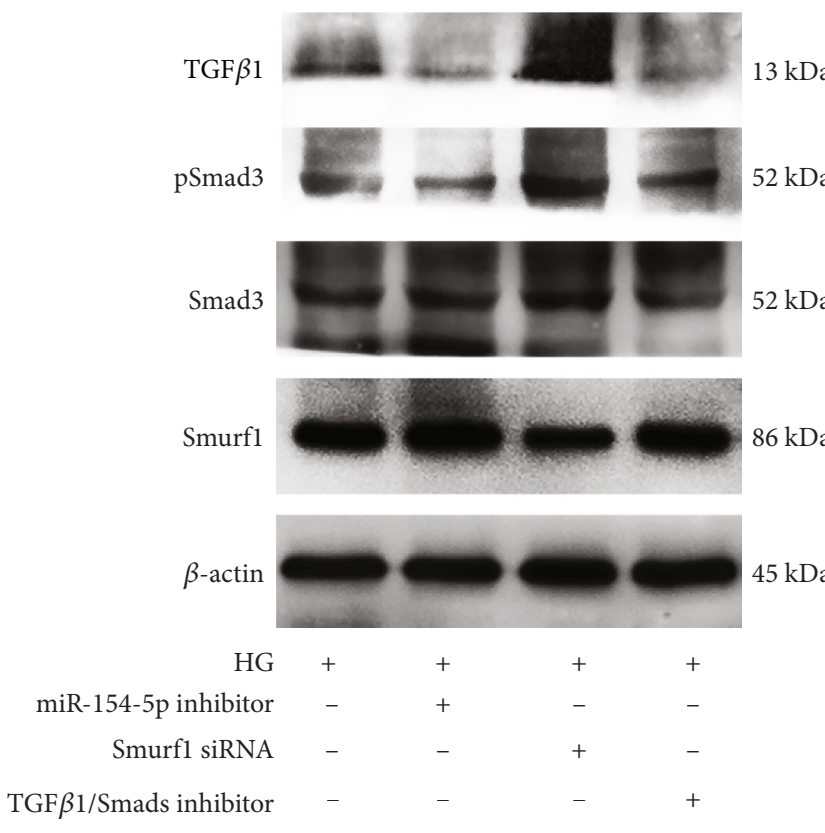

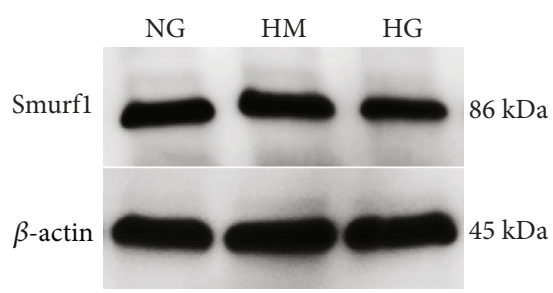

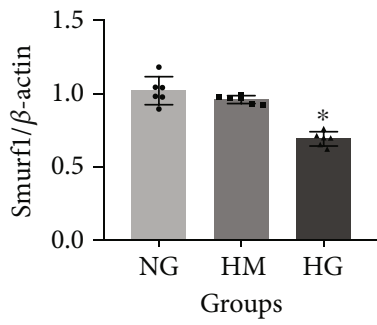

(b)
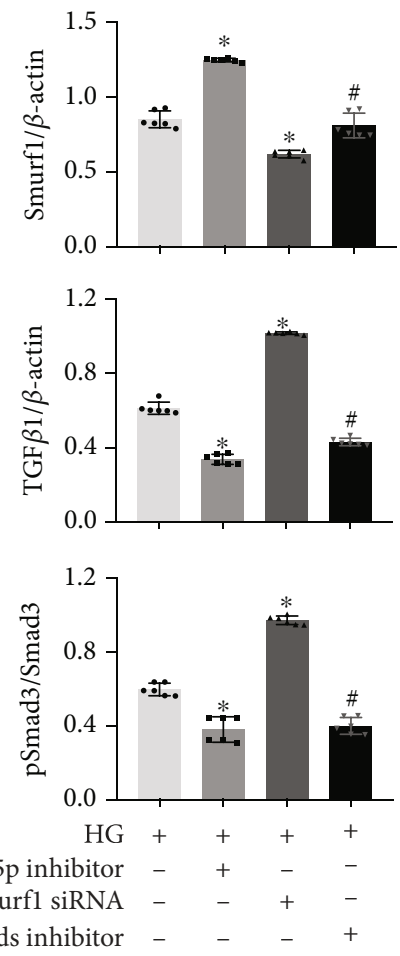

(c)

FIGURE 5: Indirect verification of the miR-154-5p target gene. Smurf1 in diabetic rats (a) and RMCs (b) cultured with high glucose. Smurf1 in RMCs with high glucose, miR-154-5p inhibitor, Smurf1 siRNA, and TGF $\beta 1 /$ Smads pathway inhibitor (c). NC: normal control; DN: diabetic nephropathy; NG: normal glucose; HM: high mannitol; HG: high glucose. ${ }^{*}$ vs. NC or NG, $P<0.05 ;{ }^{\#}$ vs $\mathrm{HG}, P<0.05$. $n=6$ samples/group.

mRNA, thereby influencing multiple cellular processes ranging from growth and development to disease generation. Studies have shown that multiple families of miRNA clusters are involved in the pathogenesis of DKD, such as let-7 family, miR-21, and miR-377, which are involved in the proliferation and apoptosis of mesangial cells under the condition of high glucose, while miR-34a-5p, miR-184, and miR-1915-5p are associated with renal tubulointerstitial fibrosis [30, 31]. Our previous studies found that compared with the normal control group, serum miR-154-5p expression in type 2 diabetic patients was significantly increased and positively correlated with UACR, HbA1c, and fibrosis factors (CTGF, VEGF, FN and $\operatorname{TGF} \beta 1)[9,10]$, indicating that human circulating miR-154$5 \mathrm{p}$ was closely related to renal fibrosis. This is the first time that miR-154-5p has been found to be associated with DKD fibrosis so far, suggesting that miR-154-5p in circulating blood may be potentially associated with blood glucose and proteinuria regulating the process of DKD glomerular fibrosis. In the high-fat diet and STZ-induced diabetic rats, FISH and PCR were used to detect the expression of miR-154-5p, and the results 


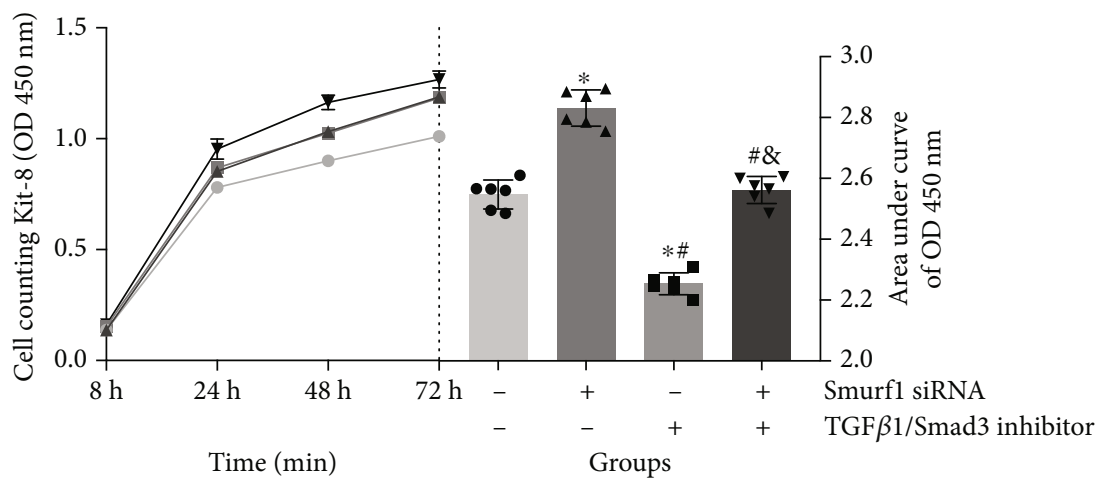

(a)
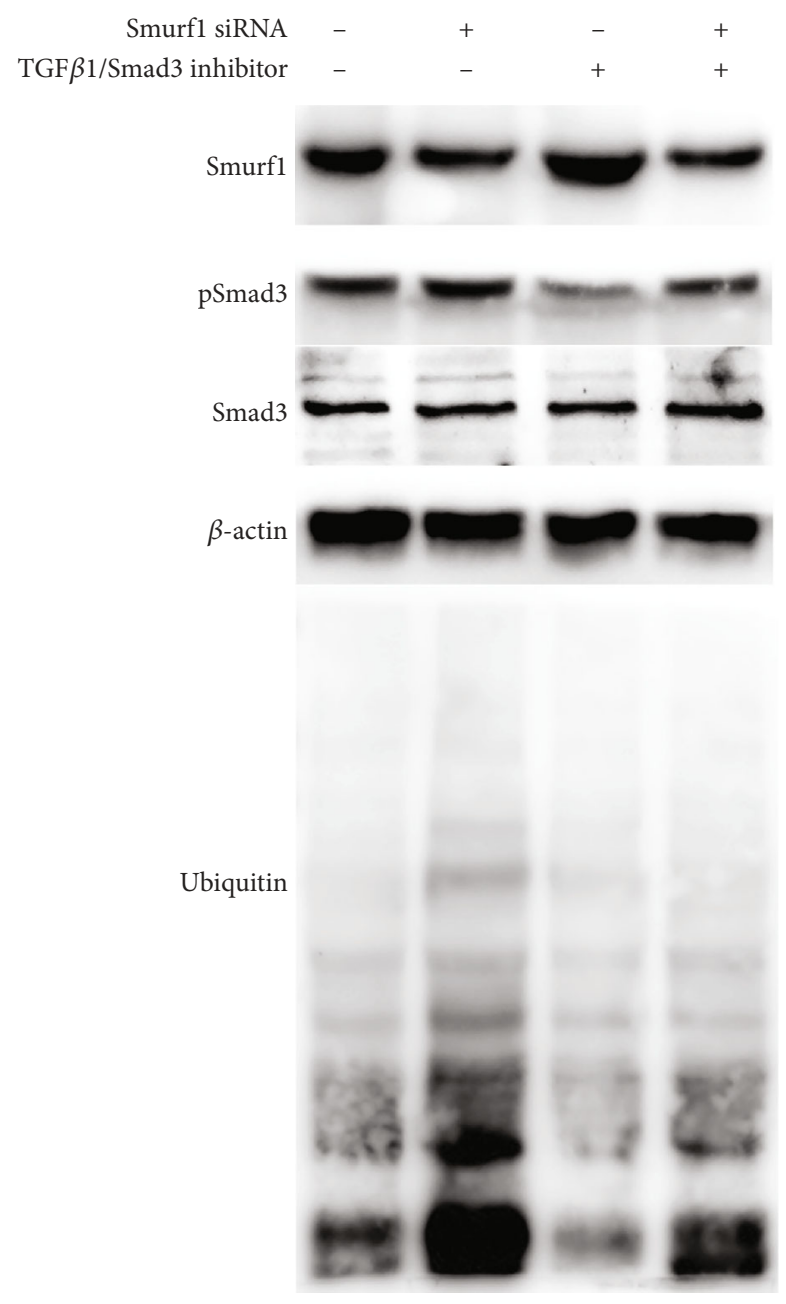

(b)

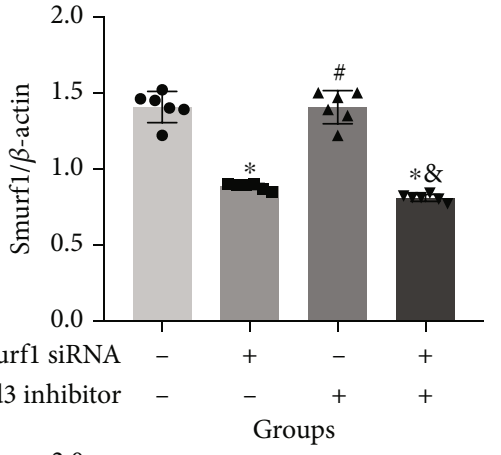

$45 \mathrm{kDa}$
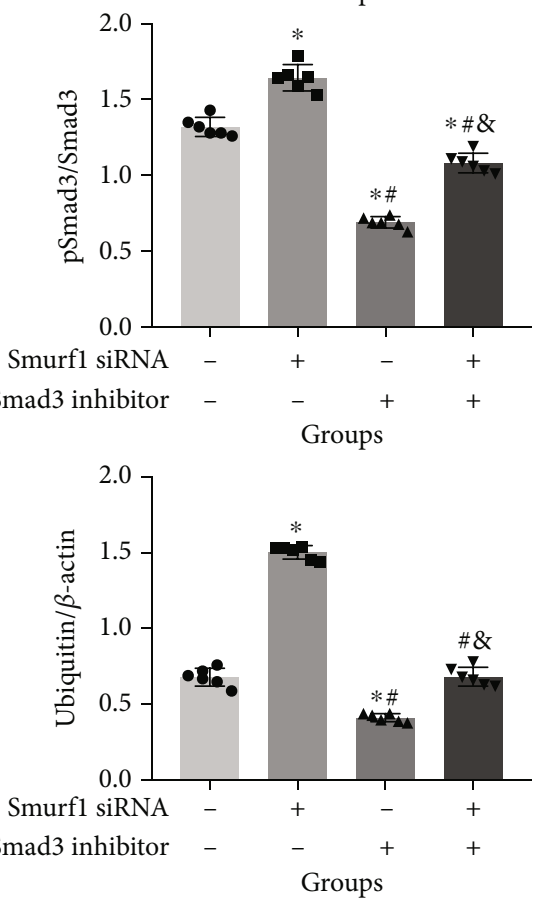

Figure 6: Continued. 

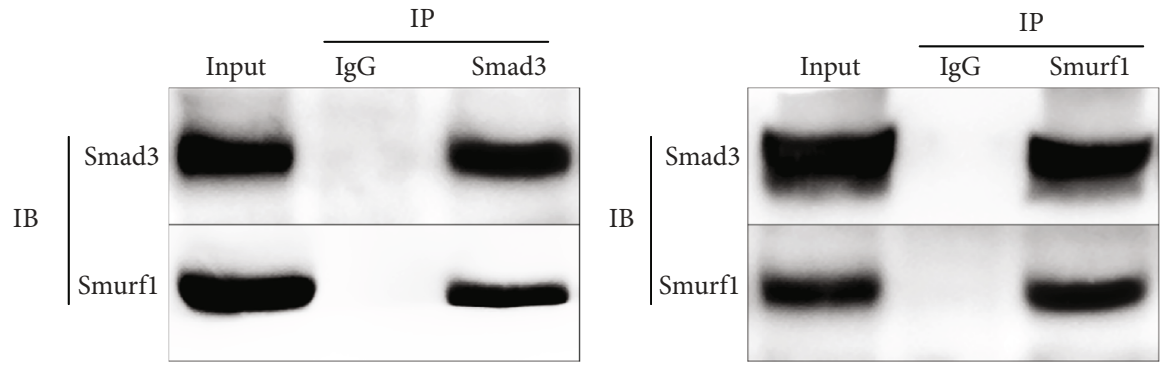

(c)

FIgURE 6: Smurf1 regulates ubiquitination through Smad3. CCK-8 cell proliferation (a) and related protein Smurf1, pSmad3/Smad3, and ubiquitin concentration (b). Co-IP verification for the combination of Smurf1 and Smad3 (c) after pretreatment with Smurf1 siRNA and TGF $\beta 1 /$ Smad3 inhibitor, SB431542. *v. Group 1, $P<0.05 ;{ }^{*}$ vs. Group $2, P<0.05 ;{ }^{\circledR}$ vs. Group 3, $P<0.05 . n=6$ samples/group.

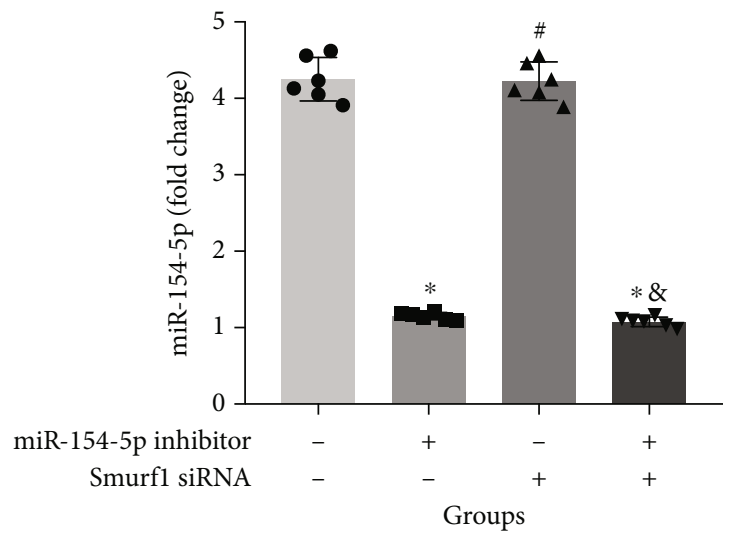

(a)

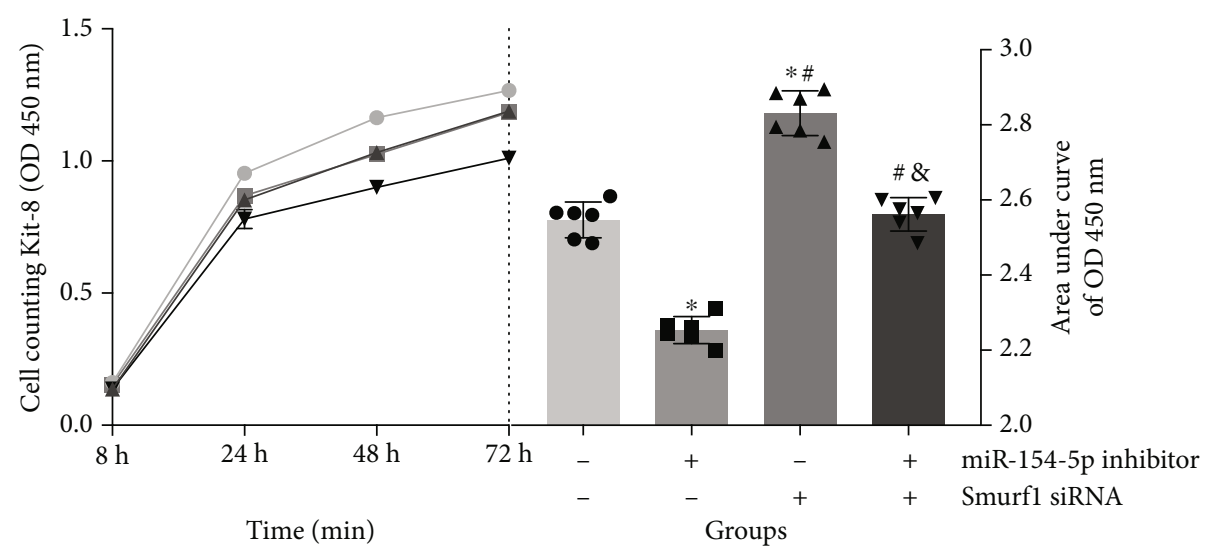

(b)

Figure 7: Continued. 


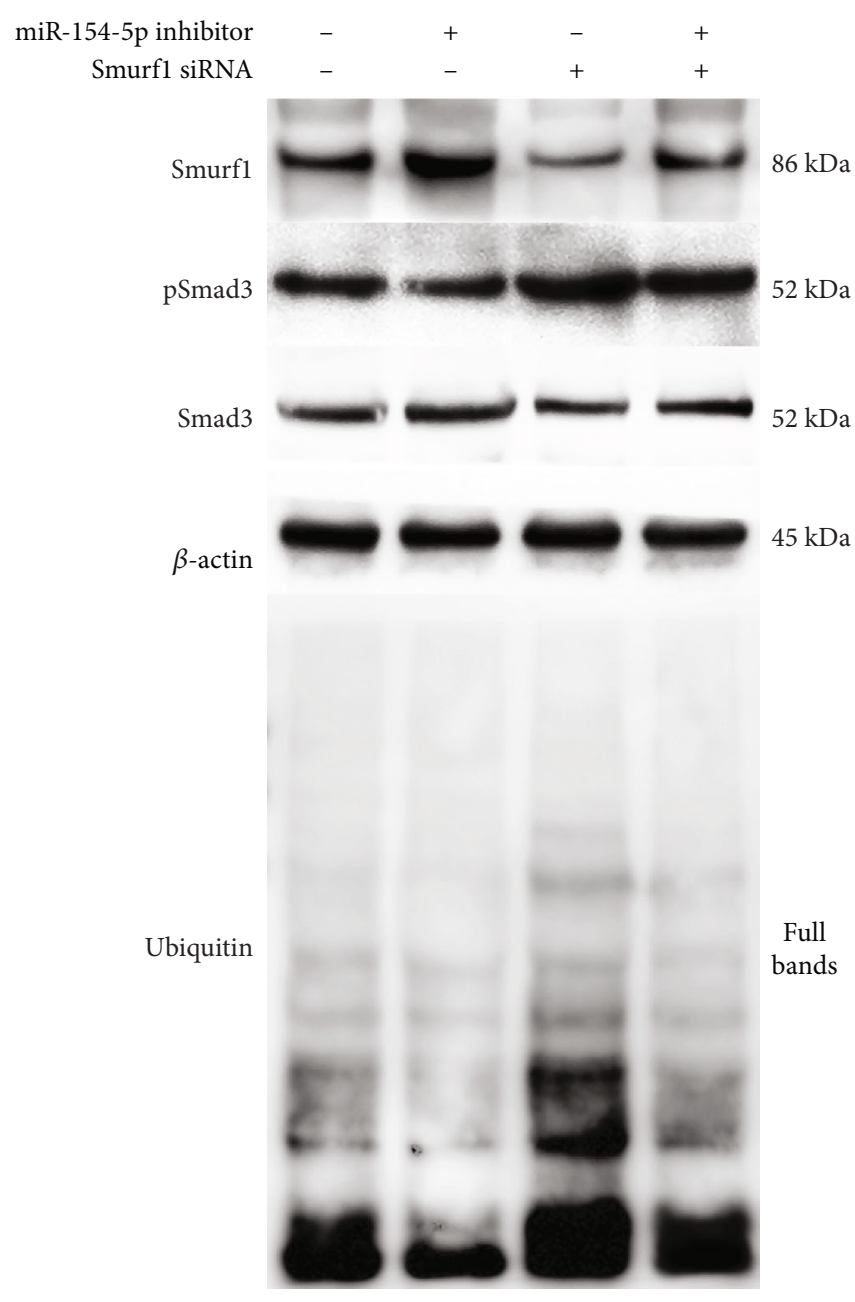

(c)
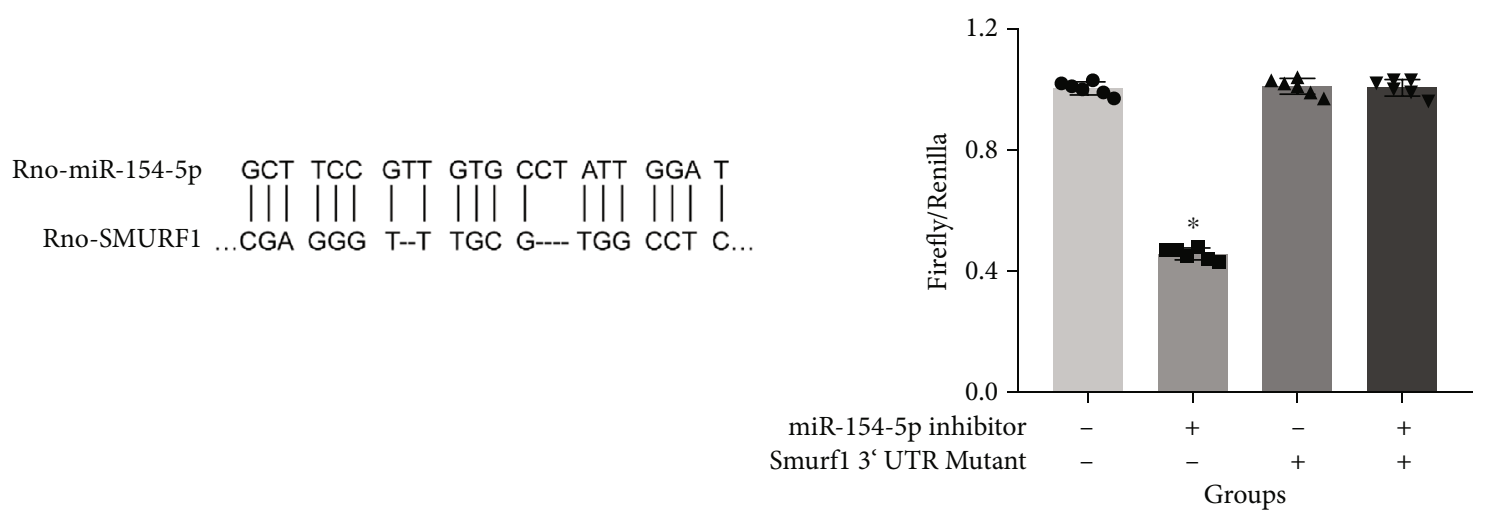

(d)

FIGURE 7: miR-154-5p influences Smurf1-mediated ubiquitination of Smad3. miRNA expression (a); CCK-8 cell proliferation (b); related protein Smurf1, pSmad3/Smad3, and ubiquitin concentration (c); luciferase verification for the binding of rno-miR-154-5p and rnoSmurf1 3' UTR (d) after pretreatment with miR-154-5p inhibitor and Smurf1 siRNA. * vs. Group 1, $P<0.05$; $^{*}$ vs. Group 2, $P<0.05$; ${ }^{\&}$ vs. Group 3, $P<0.05 . n=6$ samples/group. 


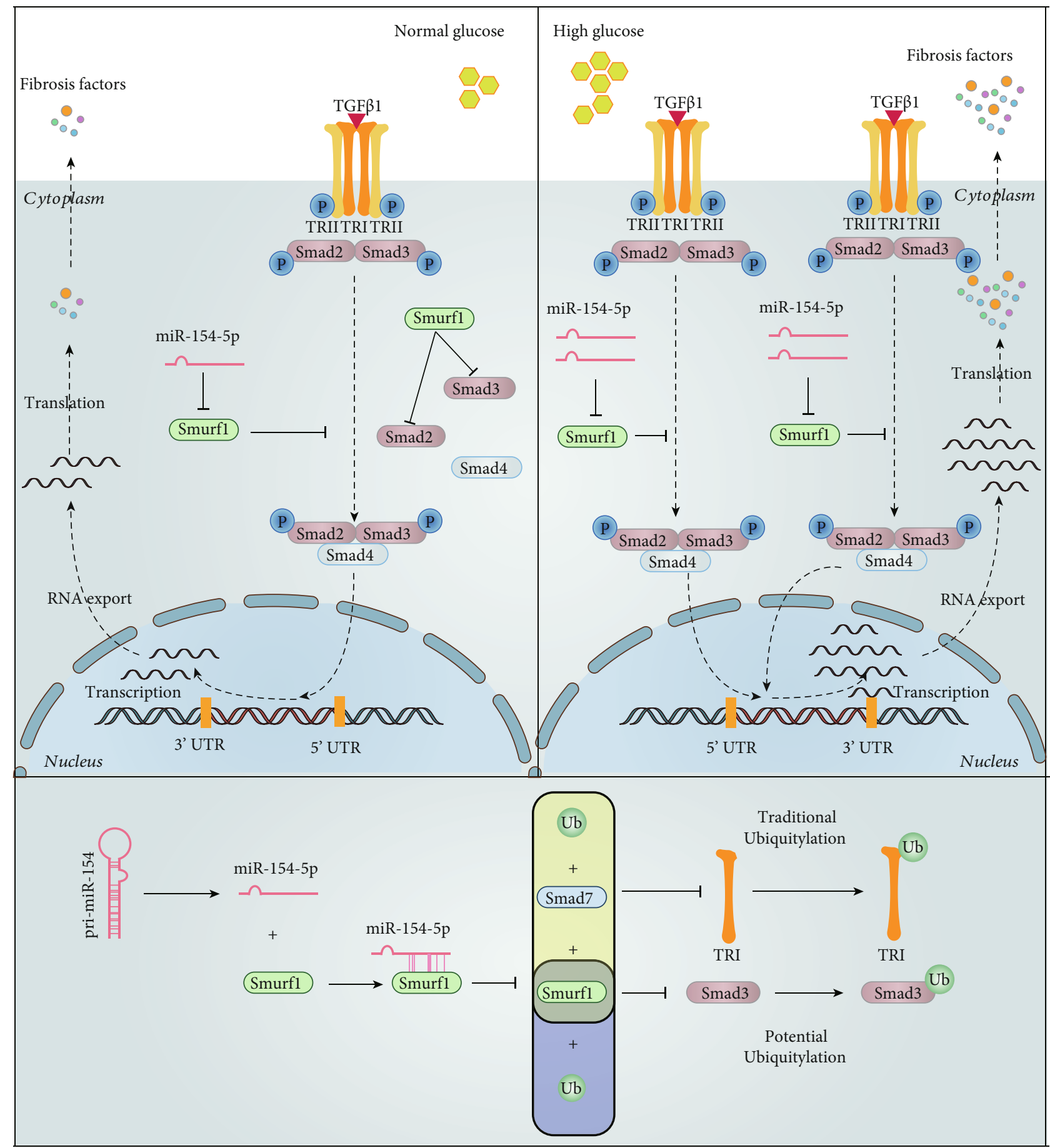

FIgURE 8: Possible mechanism. In the normal glucose state, TGF $\beta 1$ activates TRI and TRII in small amounts, causing phosphorylated Smad2 and Smad3 to bind Smad4 as polymers, which enter the nucleus and participate in transcriptional regulation of fibrosis. Smurf1 inhibits TGF $\beta 1$ signaling by regulating the classical pathway of Smad3 through TRI ubiquitination (Ub) via Smad7 or directly through the potential pathway of Smad3 ubiquitination. In the high glucose state, TGF $\beta 1 / \mathrm{Smads}$ pathway increases activation, causing more miR-154-5p to inhibit Smurf1, thus indirectly promoting TGF $\beta 1 /$ Smads pathway activation and promoting the renal fibrosis process. The effect of lentivirus for the inhibitor of miR-154-5p can block this reaction thus indirectly alleviating diabetic kidney disease.

consistently showed that miR-154-5p was highly expressed in the glomerular rather than proximal tubules of the cortex region. The glomerulus is also an important structure involved in the filtration of urinary protein, which is consistent with the results of our clinical trials.
The specific mechanism of DKD producing urine protein is thought to be related to early pathological changes of the abnormal proliferation in glomerular mesangial cells. Thus, the classic model of RMCs under high-glucose cultivation is adopted to explore DKD [20]. On the basis of our previous 
successful culturing RMCs [11, 12], we also successfully isolated the primary rat glomerular mesangial cells. Results by repeated detection of miR-154-5p showed that the expression of miR-154-5p was significantly decreased in both primary cells and cell lines pretreated by high-glucose culturing, and the cell proliferation activity was abnormally increased, which was consistent with the results in vivo, suggesting that miR154-5p may be involved in the changes of glomerular mesangial cells in the early stage of DKD.

The important pathophysiological change of DKD is glomerular fibrosis, and the TGF $\beta 1$ pathway is one of the main pathways regulating the proliferation and fibrosis of mesangial cells. TGF $\beta 1$ binds to its membrane receptor, TGF $\beta$ receptor 1 (TRI), and activates another receptor, TRII. TRII phosphorylates Smad2 and Smad3 in cells to form heteropolymer with Smad4. After nucleation, this complex binds to transcriptional coactivators or coinhibitors, thereby regulating the transcription of downstream target genes. In contrast, Smad7 binds to TRI and TRII and inhibits phosphorylation of Smad2 and Smad3, which in turn inhibits the TGF $\beta 1$ pathway transmission. Smads are involved in the pathological process of the TGF $\beta 1$ pathway in mesangial cell proliferation and fibrosis through both positive and negative regulatory effects $[6,7]$. $\mathrm{TGF} \beta 1$ and $\mathrm{pSmad} 3 / \mathrm{Smad} 3$ were significantly elevated in the diabetic animal model established in this study, which also suggested that the glomerular fibrosis of DKD was closely related to the TGF $\beta 1 /$ Smads pathway.

miR-154 is located on the miRNA-rich region in the singlestranded chromosome of mammalian 14q32 [8], and the $5^{\prime}$ arm of the precursor miR-154 (sequence: $5^{\prime}$-UAG GUU AUC CGU GUU GCC UUC G-3, mature to form miR-154$5 p$ ) has been demonstrated to be controlled by a $200 \mathrm{~kb}$ differential methylation region (DMR) in the Dlk1-Gtl2 (rodents)/ Dlk-Dio3 (human) structural domain upstream of miRNA clusters [32-34]. Previous studies have confirmed that miR$154-5 p$ is associated with the fibrosis mechanism of several diseases [35-38]. The transcription factor binding analysis showed that miR-154 is rich in Smad3 binding elements (SBEs) that mediate the TGF $\beta 1$ pathway during the growth and development stage $[35,39,40]$, suggesting that miR-154 may be involved in the TGF $\beta 1 / \mathrm{Smad} 3$ signaling pathway.

To investigate the relationship between miR-154-5p and the TGF $\beta 1 /$ Smads pathway, we treated RMCs with high glucose, miR-154-5p mimic, and inhibitor, respectively. The results showed that miR-154-5p could change the protein levels in the TGF $\beta 1 /$ Smads pathway and cell proliferation activity in RMCs. Moreover, in order to explore the regulatory mechanism of miR-154-5p involved renal fibrosis, we predicted the target genes of miR-154-5p indicating binding sites between human and rat miR-154-5p sequences and Smad ubiquitination regulatory factor 1 (Smurf1), suggesting that Smurf1 could bind with human and rat miR-154$5 p$. To verify the target genes of miR-154-5p, we detected the levels of ubiquitin-related molecule, Smurf1 in the successfully established models, and found that the expression was significantly decreased in diabetic rat renal tissues and high-glucose-cultured RMCs in vivo and in vitro.

As a member of HECT family, the E3 ubiquitin ligase, Smurf1, is a key enzyme that determines substrate specificity in the ubiquitin-modifying pathway. It can recognize ubiquitinated protein substrates and selectively regulate the ubiquitinated degradation process of effector molecules, Smads $[41,42]$. The known ubiquitination binding sites were analyzed using the NetPath/NetSlim database, finding that RhoA, Smad7, and TRI were known ubiquitin binding sites of Smurf1. Protein interaction analysis showed that Smurf1 could interact with multiple Smads in the TGF $\beta 1$ pathway. By the comparison of Smurf1 and Smad3 structures in humans and rats, Smurf1 and Smad3 had high ubiquitination binding ability and similar binding mode with Smad3. The bioinformatics analysis provided the possibility for the binding research of both. It has been reported that Smurf1 participates in the fibrosis of DKD and obstructive nephropathy by inducing the apoptosis of glomerular mesangial cells [43] and regulating the epithelial-mesenchymal transition (EMT) induced by TGF $\beta$ [44-46]. These results suggest that Smurf1 may regulate the TGF $\beta 1 /$ Smads pathway and participate in mesangial cell fibrosis, suggesting that Smurf1 may directly regulate $S m a d 3$ ubiquitination in a new way.

Rescue and luciferase experiments were used to prove the regulatory effect of miR-154-5p and Smurf1 directly and indirectly. Results showed that regulating miR-154-5p could save the abnormal proliferation and fibrosis of RMCs caused by Smurf1 regulating Smad3 ubiquitination, and miR-154-5p could bind to the Smurf1 $3^{\prime}$ UTR. Meanwhile, rescue and Co-IP experiments were used to verify the regulation of Smurf1 and Smad3 ubiquitination directly and indirectly, indicating that regulation of Smurfl could also rescue the abnormal proliferation and fibrosis of RMCs caused by Smad3 ubiquitination and that Smurf1 and Smad3 could also be directly combined. All the above experiments proved that miR-154-5p could regulate the levels of Smad3 by combining with Smurf1, thereby regulating the abnormal proliferation and fibrosis of glomerular mesangial cells and affecting the generation of proteinuria in the early DKD stage.

In conclusion, miR-154-5p can affect proliferation in glomerular mesangial cells via E3 ubiquitin ligase, Smurf1, regulating TGF $\beta 1 /$ Smads pathway, thus affecting renal fibrosis of DKD. Hopefully, the inhibitor of miR-154-5p is expected to become a potential way for the DKD treatment. The possible mechanism is shown in Figure 8.

\section{Data Availability}

The data used to support the findings of this study are included within the article.

\section{Ethical Approval}

All animals were kept in a pathogen-free environment and fed ad lab. The procedures for care and use of animals were approved by the Institutional Animal Care and Use Committee (IACUC) of China Medical University (Approval No2021115), and all experimental operations were complied with Guide for Laboratory Animal Care and Use and Animal Welfare Act. All applicable institutional and governmental regulations concerning the ethical use of animals were followed. 


\section{Conflicts of Interest}

The authors declare that they have no conflicts of interest.

\section{Authors' Contributions}

Che Bian contributed to the conceptualization, methodology, software acquisition, validation, formal analysis, investigation, resources, data curation, writing-original draft, visualization, project administration, and funding acquisition. Zhilin Luan contributed to the methodology, validation, formal analysis, resources, data curation, and writingreview and editing. Haibo Zhang, Ruijing Zhang, Jing Gao, Yuxia Wang, and Jia Li contributed to the formal analysis, resources, and data curation. Huiwen Ren contributed to the conceptualization, methodology, software, validation, formal analysis, investigation, data curation, writing-original draft, writing - review and editing, visualization, supervision, and funding acquisition.

\section{Acknowledgments}

This study was supported by the Doctoral Research Initiation Fund Project of Liaoning Province (Grant No. 2021-BS-206) and Shenyang Young and Middle-aged Innovation Support Program (RC210460). Our team would like to thank the Department of Laboratory Animal Science of China Medical University, the Central Laboratory and the Laboratory of Endocrine and Metabolism of the First Hospital of China Medical University, Laboratory of Nuclear Receptor and Major Metabolic Disease of Dalian Medical University, the Kidney Disease Center of Dalian Medical University, and the Central Laboratory of Xinhua Hospital Affiliated to Shanghai Jiaotong University School of Medicine for technical assistance and equipment support.

\section{Supplementary Materials}

Supplementary 1. Figure S1: target gene prediction of miR154-5p. Above, prediction results of RNA22 V2 on the target gene (hsa_SMURF1) of miR-154-5p (hsa_miR_154_ $5 \mathrm{p})$ in human. Below, prediction results of RNA22 V2 on the target gene (rno_SMURF1) of miR-154-5p (rno_ miR_154_5p) in rats.

Supplementary 2. Figure S2: schematic diagram of Smurf1 ubiquitination. Schematic diagram of Smurf1 as E3 ubiquitination ligase for substrate recognition (A). Ub: ubiquitin, E1-E3: ubiquitin ligase; analysis of known ubiquitination binding sites (B).

Supplementary 3. Figure S3: prediction of protein interactions and ubiquitinated binding sites. Protein interaction analysis (A), the UbiBrowser database for verification of the ubiquitin ligase recognition characteristics (B), Smurf1 with high ubiquitin binding ability with Smad2, Smad3, Smad4, and Smurf2 (marked in red); human and rat Smurf1 and Smad3 sequence alignment (C); light red for the anchored alignment area, and blue for the initiation and termination sites amino acid sequences.

\section{References}

[1] M. Afkarian, L. R. Zelnick, Y. N. Hall et al., "Clinical manifestations of kidney disease among US adults with diabetes, 19882014," JAMA, vol. 316, pp. 602-610, 2016.

[2] E. Espinel, I. Agraz, M. Ibernon, N. Ramos, J. Fort, and D. Seron, "Renal biopsy in type 2 diabetic patients," Journal of Clinical Medicine, vol. 4, pp. 998-1009, 2015.

[3] American Diabetes Association, "15. Diabetes Advocacy:Standards of medical care in diabetes-2018," Diabetes Care, vol. 41, Supplement_1, pp. S152-S153, 2018.

[4] UK NC, Chronic Kidney Disease (Partial Update): Early Identification and Management of Chronic Kidney Disease in Adults in Primary and Secondary Care, UK NC, London, 2014.

[5] American Diabetes Association, "16. Diabetes Advocacy:Standards of medical care in diabetes-2019," Diabetes Care, vol. 42, Supplement_1, pp. S182-S183, 2019.

[6] A. B. Roberts and R. Derynck, "Meeting report: signaling schemes for TGF- $\beta$ A review of the meeting "The TGF- $\beta$ Superfamily: Signaling and Development," FASEB Summer Research Conference, Tucson, Arizona, 7 to 12 July 2001," Science's STKE, vol. 2001, no. 113, p. pe43, 2001.

[7] J. Zhang, X. Zhang, F. Xie et al., "The regulation of TGF- $\beta$ / SMAD signaling by protein deubiquitination," Protein \& Cell, vol. 5, no. 7, pp. 503-517, 2014.

[8] A. Formosa, E. K. Markert, A. M. Lena et al., "MicroRNAs, miR-154, miR-299-5p, miR-376a, miR-376c, miR-377, miR381, miR-487b, miR-485-3p, miR-495 and miR-654-3p, mapped to the $14 \mathrm{q} 32.31$ locus, regulate proliferation, apoptosis, migration and invasion in metastatic prostate cancer cells," Oncogene, vol. 33, no. 44, pp. 5173-5182, 2014.

[9] H. Ren, X. Ma, Y. Shao, J. Han, M. Yang, and Q. Wang, "Correlation between serum miR-154-5p and osteocalcin in males and postmenopausal females of type 2 diabetes with different urinary albumin creatinine ratios," Frontiers in endocrinology, vol. 10, p. 542, 2019.

[10] H. Ren, C. Wu, Y. Shao, S. Liu, Y. Zhou, and Q. Wang, "Correlation between serum miR-154-5p and urinary albumin excretion rates in patients with type 2 diabetes mellitus: a cross-sectional cohort study," Frontiers in Medicine, vol. 14, pp. 642-650, 2020.

[11] H. Ren, Y. Shao, C. Wu, X. Ma, C. Lv, and Q. Wang, "Metformin alleviates oxidative stress and enhances autophagy in diabetic kidney disease via AMPK/SIRT1-FoxO1 pathway," Molecular and Cellular Endocrinology, vol. 500, article 110628, 2020.

[12] H. Ren, Y. Shao, C. Wu, C. Lv, Y. Zhou, and Q. Wang, "VASH1 regulates oxidative stress and fibrosis in diabetic kidney disease via SIRT1/HIF $1 \alpha$ and TGF $\beta 1 /$ Smad3 signaling pathways," Frontiers in Molecular Biosciences, vol. 7, p. 137, 2020.

[13] H. Jiang, S. Zou, S. Chaudhari, and R. Ma, "Short-term highglucose treatment decreased abundance of Orail protein through posttranslational mechanisms in rat mesangial cells," American Journal of Physiology. Renal Physiology, vol. 314, pp. F855-F863, 2018.

[14] H. Wang, J. Sheng, H. He et al., "A simple and highly purified method for isolation of glomeruli from the mouse kidney," American Journal of Physiology. Renal Physiology, vol. 317, pp. F1217-F1223, 2019.

[15] L. M. Wang, J. Chen, K. H. Chen, M. Y. Cai, X. Y. Wang, and Y. N. He, "Primary culture and identification of mouse renal 
proximal tubular epithelial cells," Sheng Li Xue Bao, vol. 70, pp. 406-412, 2018.

[16] J. J. Chamberlain, A. S. Rhinehart, C. F. Shaefer Jr., and A. Neuman, "Diagnosis and management of diabetes: synopsis of the 2016 American Diabetes Association Standards of Medical Care in Diabetes," Annals of Internal Medicine, vol. 164, no. 8, pp. 542-552, 2016.

[17] L. Zhang, F. Wang, L. Wang et al., "Prevalence of chronic kidney disease in China: a cross-sectional survey," Lancet, vol. 379, no. 9818, pp. 815-822, 2012.

[18] World Health Organization, WHO Global report on diabetes, 2016.

[19] C. S. Fox, K. Matsushita, M. Woodward et al., "Associations of kidney disease measures with mortality and end-stage renal disease in individuals with and without diabetes: a meta-analysis," Lancet, vol. 380, no. 9854, pp. 1662-1673, 2012.

[20] Y. Lu, L. Tang, Y. Li, and Q. He, "High glucose-induced fibronectin upregulation in cultured mesangial cells involves caveolin-1-dependent RhoA-GTP activation via Src kinase," Molecular Medicine Reports, vol. 14, pp. 963-968, 2016.

[21] T. W. Tervaert, A. L. Mooyaart, K. Amann et al., "pathologic classification of diabetic nephropathy," Journal of the American Society of Nephrology, vol. 21, no. 4, pp. 556-563, 2010.

[22] M. K. Arora and U. K. Singh, "Molecular mechanisms in the pathogenesis of diabetic nephropathy: an update," Vascular Pharmacology, vol. 58, pp. 259-271, 2013.

[23] B. L. Riser, F. Najmabadi, B. Perbal et al., "CCN3/CCN2 regulation and the fibrosis of diabetic renal disease," Journal of cell communication and signaling, vol. 4, pp. 39-50, 2010.

[24] D. Macconi, G. Remuzzi, and A. Benigni, "Key fibrogenic mediators: old players. Renin-angiotensin system," Kidney international supplements, vol. 4, no. 1, pp. 58-64, 2014.

[25] C. Zoja, M. Locatelli, D. Corna et al., "Therapy with a selective cannabinoid receptor type 2 agonist limits albuminuria and renal injury in mice with type 2 diabetic nephropathy," Nephron, vol. 132, pp. 59-69, 2016.

[26] O. Ellina, A. Chatzigeorgiou, S. Kouyanou et al., "Extracellular matrix-associated (GAGs, CTGF), angiogenic (VEGF) and inflammatory factors (MCP-1, CD40, IFN-gamma) in type 1 diabetes mellitus nephropathy," Clinical Chemistry and Laboratory Medicine, vol. 50, pp. 167-174, 2012.

[27] X. Li, T. T. Wu, J. Chen, and W. Qiu, "Elevated expression levels of serum insulin-like growth factor-1, tumor necrosis factor- $\alpha$ and vascular endothelial growth factor 165 might exacerbate type 2 diabetic nephropathy," Journal of diabetes investigation, vol. 8, no. 1, pp. 108-114, 2017.

[28] S. Malik, K. Suchal, S. I. Khan et al., "Apigenin ameliorates streptozotocin-induced diabetic nephropathy in rats via MAPK-NF- $\kappa$ B-TNF- $\alpha$ and TGF- $\beta 1$-MAPK-fibronectin pathways," American Journal of Physiology. Renal Physiology, vol. 313, no. 2, pp. F414-F422, 2017.

[29] A. S. Chang, C. K. Hathaway, O. Smithies, and M. Kakoki, "Transforming growth factor- $\beta 1$ and diabetic nephropathy," American Journal of Physiology. Renal Physiology, vol. 310, no. 8, pp. F689-F696, 2016.

[30] P. Trionfini and A. Benigni, "MicroRNAs as master regulators of glomerular function in health and disease," Journal of the American Society of Nephrology, vol. 28, pp. 1686-1696, 2017.

[31] S. Bagga, J. Bracht, S. Hunter et al., "Regulation by let-7 and lin-4 miRNAs results in target mRNA degradation," Cell, vol. 122, pp. 553-563, 2005.
[32] H. Seitz, H. Royo, M. L. Bortolin, S. P. Lin, A. C. FergusonSmith, and J. Cavaille, "A large imprinted microRNA gene cluster at the mouse Dlk1-Gtl2 domain," Genome Research, vol. 14, pp. 1741-1748, 2004.

[33] A. Dixon-McIver, P. East, C. A. Mein et al., "Distinctive patterns of microRNA expression associated with karyotype in acute myeloid leukaemia," PLoS One, vol. 3, article e2141, 2008.

[34] Y. Altuvia, P. Landgraf, G. Lithwick et al., "Clustering and conservation patterns of human microRNAs," Nucleic Acids Research, vol. 33, pp. 2697-2706, 2005.

[35] J. Milosevic, K. Pandit, M. Magister et al., "Profibrotic role of miR-154 in pulmonary fibrosis," American Journal of Respiratory Cell and Molecular Biology, vol. 47, pp. 879-887, 2012.

[36] P. Dong, W. J. Liu, and Z. H. Wang, "MiR-154 promotes myocardial fibrosis through beta-catenin signaling pathway," European Review for Medical and Pharmacological Sciences, vol. 22, pp. 2052-2060, 2018.

[37] L. Y. Sun, Z. D. Bie, C. H. Zhang, H. Li, L. D. Li, and J. Yang, "MiR-154 directly suppresses DKK2 to activate Wnt signaling pathway and enhance activation of cardiac fibroblasts," Cell Biology International, vol. 40, pp. 1271-1279, 2016.

[38] B. C. Bernardo, S. S. Nguyen, X. M. Gao et al., "Inhibition of miR-154 protects against cardiac dysfunction and fibrosis in a mouse model of pressure overload," Scientific Reports, vol. 6, no. 1, p. 22442, 2016.

[39] H. Yang, L. Wang, J. Zhao et al., "TGF- $\beta$-activated SMAD3/4 complex transcriptionally upregulates_N $\mathrm{N}_{-}$-cadherin expression in non-small cell lung cancer," Lung Cancer, vol. 87, no. 3, pp. 249-257, 2015.

[40] K. V. Pandit, J. Milosevic, and N. Kaminski, "MicroRNAs in idiopathic pulmonary fibrosis," Translational Research, vol. 157, pp. 191-199, 2011.

[41] J. Wei, M. Ferron, C. J. Clarke et al., "Bone-specific insulin resistance disrupts whole-body glucose homeostasis via decreased osteocalcin activation," The Journal of Clinical Investigation, vol. 124, pp. 1-13, 2014.

[42] J. Shimazu, J. Wei, and G. Karsenty, "Smurf1 inhibits osteoblast differentiation, bone formation, and glucose homeostasis through serine 148," Cell Reports, vol. 15, pp. 27-35, 2016.

[43] S. Kume, M. Haneda, K. Kanasaki et al., "SIRT1 inhibits transforming growth factor beta-induced apoptosis in glomerular mesangial cells via Smad7 deacetylation," The Journal of Biological Chemistry, vol. 282, pp. 151-158, 2007.

[44] W. Gong, Z. Chen, Y. Zou et al., "CKIP-1 affects the polyubiquitination of Nrf2 and Keap1 via mediating Smurf1 to resist HG-induced renal fibrosis in GMCs and diabetic mice kidneys," Free Radical Biology \& Medicine, vol. 115, pp. 338$350,2018$.

[45] H. Fukasawa, T. Yamamoto, A. Togawa et al., "Down-regulation of Smad7 expression by ubiquitin-dependent degradation contributes to renal fibrosis in obstructive nephropathy in mice," Proceedings of the National Academy of Sciences of the United States of America, vol. 101, pp. 8687-8692, 2004.

[46] Z. Chen, X. Sun, Q. Chen et al., "Connexin32 ameliorates renal fibrosis in diabetic mice by promoting K48-linked NADPH oxidase 4 polyubiquitination and degradation," British Journal of Pharmacology, vol. 177, pp. 145-160, 2020. 